\title{
LA RECONSTRUCCIÓN DE LA BIBLIOTECA HIPOTÉTICA DE FRANCISCO DE QUEVEDO viejos problemas y nuevos hallazgos ${ }^{1}$
}

\author{
ISABEL PÉREZ CUENCA \\ Universidad CEU San Pablo
}

En el año 1971, en el IV Congreso de la Asociación Internacional de Hispanistas, Maxime Chevalier afirmaba que los inventarios de las bibliotecas particulares representan una fuente de datos insustituibles y valiosos para ayudar a conocer la historia de la lectura y de la cultura de la España del Siglo de $\mathrm{Oro}^{2}$. Pero tras la localización de esos inventarios, la posterior identificación de autores y títulos es tarea lenta, pues no es ocasional que esos repertorios de libros se limiten a ofrecer información genérica o muy sucinta de las obras en ellos registradas, y esos breves datos, las más de las veces, apenas permiten determinar el nombre de autor y mucho menos el título de la obra ${ }^{3}$. Aún más complejo resulta hallar la edición concreta del texto reseñado, la ausencia en las referencias de información básica como el lugar y año de impresión

${ }^{1}$ Este trabajo se ha realizado en el marco del proyecto «Biblioteca Digital Siglo de Oro IV» (BIDISO IV), FFI 2012-34362 (1/2/2013 a 31/1/2016) financiado por el MINECO.

${ }^{2}$ M. Chevalier, «Para una historia de la cultura del Siglo de Oro (Cuestiones de método)», en E. Bustos Tovar (ed.), Actas del IV Congreso de la AIH, Universidad de Salamanca, 1971, 331-340, pág. 333.

${ }^{3}$ Es frecuente hallar en estos repertorios descripciones como las siguientes: «un tomo en octavo de religión», «un tomo sobre Job en octavo», «de Penitencia», «de Contratos, todos son tomos de a folio», «Dos tomos grandes», «Otros dos tomos grandes» y «un libro de a octavo en griego». 
convierte en ocasiones este objetivo en una meta casi inalcanzable. Por último, encontrar el ejemplar descrito en los inventarios depende la mayoría de las veces más del azar que de cualquier método sistemático que se pretenda aplicar en la localización de los libros que pertenecieron a un determinado personaje, en el caso que nos ocupa a Francisco de Quevedo ${ }^{4}$.

Para reconstruir la biblioteca hipotética de Quevedo es imprescindible recurrir a todos los repertorios conocidos que ofrecen alguna vía o camino a seguir para determinar los libros que el escritor tuvo en sus manos y establecer su posible paradero. Los rescatados del Archivo Histórico de Protocolos de Madrids por Felipe C. R. Maldonado ${ }^{6}$ son los únicos que certifican libros propiedad de Quevedo. Estamos seguros de que esas listas están incompletas, Maldonado ya advirtió que:

[...] las ciento setenta y seis obras que se consignan en los inventarios no son sino una parte de cuantas poseyó Quevedo, puesto que faltan casi todos los libros que hasta hoy se han descubierto con su firma.

Pronto se unieron a esa labor los índices de la librería del monasterio de San Martín de Madrid, lugar al que fueron a parar bastantes ejemplares del escritor áureo. Así pues, junto a Quev. 1646 se sumaron, en el proceso de identificación y localización de la colección bibliográfica de Quevedo, tres índices o alfabetos

\footnotetext{
4 Desde hace algunos años (2007) se trabaja en la creación y desarrollo de una base de datos de Inventarios y Bibliotecas del Siglo de Oro (IBSO), entre los que se incluyen dos relacionados con Francisco de Quevedo: 1) Inventario de la librería que poseía en su palacio del Puerto de Santa María don Antonio-Juan Luis de la Cerda, VII duque de Medinaceli [1673], Archivo Ducal de Medinaceli, Sec. Histórica, Caja 30, doc. no 22. Se cita por M. C. Álvarez Márquez, «La biblioteca de don Antonio Juan Luis de la Cerda, VII duque de Medinaceli, en su Palacio del Puerto de Santa María (1673)», Historia, Instituciones, Documentos, 15, 1988, 251-381, se hará referencia a él con la abreviatura Med. 1673, seguida, cuando sea necesario, del [número de partida] asignado por Álvarez Márquez a cada ítem o asiento bibliográfico, y 2) el índice de la biblioteca de San Martín fechado en 1788 (ms. de la Real Academia de la Historia 9/2099). La finalidad de dicho proyecto no solo es identificar autores y títulos que figuran en los repertorios, sino también determinar la edición y localizar el ejemplar, con la pretensión, tal como se dice en la página web de presentación, de «establecer la Biblioteca hipotética de un escritor - léase Quevedo-, formada por las lecturas que sabemos que realizó, bien porque cita con detalle las obras o porque dejó rastros físicos en ejemplares recuperados (firmas, exlibris, etc.)», SIELAE (Seminario Interdisciplinar para el Estudio de la Literatura Áurea Española), Inventarios y bibliotecas del Siglo de Oro [en línea], Universidade da Coruña, <http://www.bidiso.es/InventariosYBibliotecas/> [consulta: $22 \mathrm{de}$ febrero de 2015].

${ }^{5}$ Archivo Histórico de Protocolos de Madrid, Antonio Gómez, Protocolo 8471, fols. 135r-142v.

${ }^{6}$ F. C. R. Maldonado, «Algunos datos sobre la composición y dispersión de la biblioteca de Quevedo», en Homenaje a la memoria de don Antonio Rodríguez-Moñino, 1910-1970, Castalia, Madrid, 1975, págs. 405-420; publicado de nuevo por C. Fernández y S. Simões, «Nuevas aportaciones a la biblioteca de Francisco de Quevedo» [en línea], Manuscrt. Cao, 11, 2011, 1-54, <http://www.edobne.com/manuscrtcao/> [consulta: 22 de febrero de 2015]. Será citado con la abreviatura Quev. 1646, seguida del [número otorgado a cada ítem por Maldonado/número adjudicado por Fernández y Simões].

7 F. C. R. Maldonado, loc. cit., págs. 406-407, nota 6. Quince son los libros firmados por Quevedo que entonces se conocían.
} 
de aquella biblioteca, fechados en 1699, 1730 y $1788^{8}$, y sobre todo el último de ellos con más 7.500 obras ordenadas por nombre de autor, seguido de título, lugar y año de impresión, además con indicación de número de tomos y signatura topográfica. En contadas ocasiones se han empleado S. Martín 1699 y 1730, ambos de menor utilidad que el mencionado por carecer las referencias bibliográficas de los datos de impresión?.

Junto a estos repertorios se convierte en información de sumo interés cualquier otra noticia que ofrezca alguna luz sobre los libros coleccionados por el VII duque de Medinaceli, por haberse unido a ellos una parte de la biblioteca de Francisco de Quevedo. Recordemos que, desde comienzos del siglo XX, gracias a las Series de los más importantes documentos del archivo y biblioteca del duque de Medinaceli de Antonio Paz y Meliá ${ }^{10}$, disfrutamos de variadas noticias sobre la composición y fortuna de la librería de la casa de Medinaceli. Por Paz y Meliá sabemos que junto a los libros de la colección ducal se reunieron, además de los de Quevedo, algunos pertenecientes a Ambrosio de Morales, Pero Mexía, Juan de Mal Lara y al conde-duque de Olivares entre otros ${ }^{11}$; a su vez

${ }^{8}$ De los tres índices, dos se conservan en la Biblioteca Nacional de España (BNE): ms. 13647 del año 1966, y el ms. 1908 de 1730, el otro se halla en la Biblioteca de la Real Academia de la Historia (BRAH), ms. 9/2099 de 1788. A partir de ahora los índices de San Martín se citarán de forma abreviada: S. Martín año. No son estos los únicos índices que conocemos del monasterio madrileño: Ýndice extraordinario de la librería de San Martín de Madrid, siendo abad el Rmo. P. Fr. Plácido Vicente, año de 1789 (BNE, ms. 18839); Índice de todos los manuscriptos que se hallan hoy 23 de agosto de 1770 en este archivo de San Martín de Madrid...; Libros impresos...; Libros prohibidos..., todos tres copiados en el Índice y inventario de todas las escripturas del archivo de esta real casa y parroquia de San Martín de Madrid. Ordenado y dispuesto por mandado de n. p. el mro. fr. Bernardo Gayoso..., año 1769 (BNE, ms. 1916, fols. 297-303); Inventario de manuscritos de San Martín (Biblioteca del Real Seminario de Zaragoza, no 9451). Es de enorme interés el artículo de G. de Andrés sobre el fondo manuscrito que poseyó el monasterio madrileño, «Una valiosa colección de códices del convento benedictino de S. Martín de Madrid», Anales del Instituto de Estudios Madrileños, XXX, 1991, págs. 251-259. El real monasterio de San Martín de Madrid con total seguridad añadió a su biblioteca libros firmados, anotados y subrayados por Francisco de Quevedo junto a los del VII duque de Medinaceli.

${ }^{9}$ Pueden leerse unas descripciones más detalladas de S. Martín 1699, 1730 y 1788 en I. Pérez Cuenca, «Las lecturas de Quevedo a la luz de algunos impresos de su biblioteca», Perinola. Revista de investigación quevediana, 7, 2003, págs. 297-231.

${ }^{10}$ A. Paz y Meliá, Series de los más importantes documentos del Archivo y Biblioteca del Duque de Medinaceli [s. n.], Madrid, 1915-1922, 2 vols.

${ }^{11}$ Según Paz y Meliá (loc. cit., II. serie, pág. 551) 48 volúmenes conservan notas autógrafas de Ambrosio de Morales, 30 de Juan de Mal Lara (Sevilla, 1547 a 1568) y 1 de Quevedo. Hemos hallado algún ejemplar de Ambrosio de Morales, de Pero Mexía y de Juan de Mal Lara en la Biblioteca de la Fundación Bartolomé March que confirman las palabras de Paz y Meliá, son los siguientes: 1) Petri Bembi Opuscula aliquot: quae sequenti pagella connumerantur. Lugduni: apud Gryphium, 1532. En portada, de mano de Ambrosio de Morales, se lee: «Tiempo fue, que tiempo no fue. Amb. de Morales/Nichil constat loco stabili et nichil/quo stat loco stabit»; varias páginas han sido anotadas a mano por Ambrosio de Morales. Este ejemplar de Bembo conserva el exlibris de la Biblioteca del duque de Medinaceli y Santisteban. Signatura: B87-A-14; 2) Sebastiani Corradi Egnatius, sive Quaestura, cuius praecipua capita haec sunt M. T. Ciceronis 
revela que el corpus bibliográfico era rico en materias y escritores de diferentes épocas y que se coleccionaron tanto manuscritos como impresos, aunque como es de suponer, en mayor número los segundos que los primeros ${ }^{12}$. Sobre bibliotecarios, índices, fondos, procedencias, traslados, mermas y dispersiones de tan valioso fondo hace referencia Paz y Meliá en diversos lugares de los dos tomos que componen las Series y, aunque conocidos, procedo a relatar someramente algunos datos relacionados con la venta de parte de la colección de Medinaceli al monasterio de San Martín, por la importancia que tienen para vincular en el momento apropiado los libros del vII duque - y por ende los de Quevedo-, con los del monasterio, ya que son varios los años propuestos para la adquisición de la librería de Antonio Juan Luis de la Cerda por parte de los benedictinos. Hemos de tener en cuenta que establecer la fecha concreta en la que cambian de mano los libros del duque es asunto de cierta relevancia a la hora de acometer la labor de reconstrucción de la biblioteca hipotética de Quevedo a través de los índices o alfabetos de la librería del monasterio.

En 1673, dos años después de la muerte del VII duque de Medinaceli, se confecciona el inventario - compuesto por 1.471 partidas - de los libros que tenía en el Puerto de Santa María, tasados en ochenta y seis mil ochocientos treinta y siete reales por Francisco de Castro, librero del Puerto ${ }^{13}$. Poco antes de

vita undique collecta, \& defensa. Multa e Plutarcho, caeterisque Graecis conversa. Multa comprobata. Multa confutata. Oratio Sallustii in Ciceronem confutata, \& explicata. Oratio Ciceronis in Sallustium confutata, \& explicata. M. T. Ciceronis opera numerata, \& digesta. M. T. Ciceronis filii vita. Q. T. Ciceronis fratris vita. Q. T. Ciceronis filii vita. Q. T. Ciceronis fratris Liber de Petitine consulatus, explicatus. Eorum, qui scribunt apud Ciceronem, vitae demonstratae... Basileae: per Ioannem Oporinum, 1556. Como en el anterior, Ambrosio de Morales escribió en la portada: «Tiempo fue, que tiempo no fue. Amb. de Morales Cordub.», también conserva el exlibris de la Biblioteca del duque de Medinaceli y Santisteban. Signatura: B-79-C-09; 3) Lilii Gregorii Gyraldi Ferrariensis Dialogi duo de poetis nostrorum temporum...; eiusdem epistola uersu conscripta, in qua agitur de incommodis, quae in direptione Vrbana passus est, ubi item et quasi catalogus suorum amicorum poetarum et defletur interitus Herc. Card. Rhang...; eiusdem progymnasma aduersus literas \& literatos et eiusdem quaedam carmina et item Caelij Calcagnini. Florentiae: [s. n.], 1551. En portada, nota autógrafa de Ambrosio de Morales: «Tiempo fue, que tiempo no fue. Ambrosio de Molares Cordubu.», y no falta el exlibris de la Biblioteca del duque de Medinaceli y Santisteban, además del de Bartolomé March. Signatura: 940623; 4) Lilii Gregorii Gyraldi ferrariensis dialogi tres de scena et poetarum scenicorum historia [s. 1: s. n., 1541]. Junto a la habitual anotación autógrafa de Ambrosio de Morales: «Tiempo fue que tiempo no fue. Ambro. de Morales. Cordub.», se conservan los exlibris de las bibliotecas del duque de Medinaceli y Santisteban y de Bartolomé March. Este ejemplar está falto de portada. Signatura: 940616; 5) Theoricarum novarum textus Georgii Purbachii cun vitili ac preclarissima expositione Domini Francisci Capuani de Manfredonia [París, 1515]; en la portada se lee la siguiente nota manuscrita: «es de Pero Mexía»; también anotaciones en los márgenes de distintas páginas en latín y en griego. Signatura: B98-D-02. Agradecemos a Fausto Roldán y a Pilar González Rodríguez, director y bibliotecaria de la Biblioteca de la Fundación Bartolomé March, las muchas ayudas brindadas que nos permiten avanzar en nuestra búsqueda de impresos procedentes de la biblioteca ducal de Medinaceli.

${ }^{12}$ M. C. Álvarez Márquez, op. cit., pág. 252, contabiliza 27 obras manuscritas en Med. 1673.

${ }^{13}$ Adviértase que este inventario solo registra los libros de la biblioteca del Puerto, no se ha de descartar la posibilidad de que el viI duque de Medinaceli tuviese más libros en otros lugares. 
fallecer la duquesa de Cardona se venden los libros del vII duque Medinaceli al real monasterio de San Martín de Madrid en algo más de veinte mil reales ${ }^{14}$. La venta de libros, afirma sin argumentar ni documentar Paz y Meliá cuando aborda las procedencias, se produce en el año $1763^{15}$. Sin embargo esta fecha ha sido desestimada por los quevedistas ${ }^{16} \mathrm{y}$, desde la publicación del artículo de Maldonado en el año $1975^{17}$, se ha considerado que los libros son adquiridos por los benedictinos de Madrid antes de 1697, año en el que muere Catalina Antonia de Cardona Aragón y Sandoval, IX duquesa de Cardona, casada con el VIII duque de Medinaceli, muerto este en 1691. Felipe Maldonado en su estudio no desarrolla argumento alguno a favor del año 1697, sin embargo en la correspondencia que cruza con James O. Crosby se aborda este asunto y se discute el año propuesto por Paz y Meliá18:

Sobre la fecha en que se vendieron libros del duque de Medinaceli al Monasterio de San Martín: véase lo que digo en mi libro sobre la poesía de Quevedo, cuya copia mecanografiada tiene V., capítulo MSS NO AUTÓGRAFOS, sección sobre Ausias March ${ }^{19}$. Tengo la impresión que tal venta fue antes de las fechas de 1762-1763 que menciona V.

El libro de poesía mencionado por Crosby es En torno a la poesía de Quevedo, aquí se hace referencia a una noticia del padre Martín Sarmiento acerca de un ejemplar de Ausias March propiedad de Quevedo que el benedictino consultó en la biblioteca del monasterio, inserta en sus Memorias para la historia de la poesía y poetas españoles, con dedicatoria fechada el 21 de abril de $1745^{20}$, aunque la obra fue publicada, escribe Crosby, «treinta años

${ }^{14}$ A. Paz y Meliá, op. cit., I. serie, págs. XXI-XXII; la misma información la repite M. C. Álvarez Márquez, op. cit., págs. 260-261.

${ }^{15}$ A. Paz y Meliá, loc. cit., II. serie, pág. 9.

${ }^{16}$ Los trabajos de H. Ettinghausen, «Quevedo Marginalia: His Copy of Florus' EPITOME», Modern Language Review, 59, 1964, págs. 391-398, y de J. O. Crosby, En torno a la poesía de Quevedo, Castalia, Madrid, 1967, sin abordar abiertamente el problema del año de venta, permiten suponer que se produce en fecha más temprana. H. Etthinghausen (pág. 392) hace referencia expresa a la fecha de venta de la colección de Medinaceli y comprueba que algunos de los libros que pertenecieron a Quevedo, conocidos en aquel momento, figuran tanto en el índice de San Martín datado en 1730 como en el del año 1788.

17 Véase F. R. C. Maldonado, op. cit., pág. 408, nota 9.

${ }_{18}$ Carta inédita de Crosby a Maldonado, 28 de abril de 1966.

${ }^{19} \mathrm{El}$ texto al que hace referencia J. O. Crosby, En torno a la poesía de Quevedo, pág. 81, es el siguiente: "A mediados del siglo XVIII el erudito padre Martín Sarmiento, discípulo predilecto de Benito Jerónimo Feijóo, iba redactando en el monasterio benedictino de San Martín de Madrid un estudio que había de titularse Memorias para la historia de la poesía y poetas españoles. Aunque se firmó la dedicatoria al Cardenal Silvio Valenti Gonzaga el 21 de abril de 1745 , la obra no se publicó sino treinta años más tarde, cuando el autor ya se había muerto».

${ }^{20}$ Reproduzco el texto de Martín Sarmiento, Memorias para la historia de la poesía y poetas españoles, EMECÉ, Buenos Aires, 1952, págs. 265-266: «El exemplar del dicho año de 1539, con caracteres góthicos, se conserva en la Bibliotheca de este monasterio de S. Martín; y merece alguna recomendación, pues le poseyó el célebre D. Francisco Quevedo, y tiene varias notas 
más tarde, cuando el autor ya se había muerto ${ }^{21}$. Maldonado, atendiendo a la observación de Crosby, estudia un trabajo de Etthighausen sobre el ejemplar de Floro en el que aborda este problema ${ }^{22}$, y, de acuerdo con la puntualización de su corresponsal, rechaza la fecha apuntada por Paz y Meliá23:

Ya he tomado notas de las fechas que V. y Ettighausen dan acerca de la venta de la librería del duque de Medinaceli. Agrego lo que me dice Paz. En este aspecto, como comprenderá, he preparado toda la información posible, para no perder el tiempo inútilmente. Las fechas, desde luego, no podían ser 1762-3, porque había visto los libros mucho antes Sarmiento.

Días después Maldonado escribe a Crosby para presentar uno de los índices del monasterio de San Martín conservado en la Biblioteca Nacional de España (BNE, ms. 1908) con el que contradirá por otra vía más la datación propuesta por Paz y Meliá24:

Recuerde que el catálogo de la Biblioteca de San Martín que incluye los libros del duque de Medinaceli es de 1730, pero ¿Cuándo habían ingresado estos libros? Porque la fecha que da Paz es disparatada (1.471 libros en 1763), 36 años después del catálogo citado y 18 después de haber concluido su estudio Martín Sarmiento.

Además no se ha de olvidar que Ettinghausen, unos años antes, al estudiar el ejemplar de Floro con autógrafos de Quevedo, comprobó que varios volúmenes que anotó el escritor se hallaban en los índices fechados en 1730 y 1788 de la biblioteca de San Martín 25 .

A todo lo antecedente se ha de unir un trabajo de M. Carmen Álvarez Márquez publicado en $1988^{26}$, que ha sido ignorado desafortunadamente por los quevedistas. El estudio da a conocer una pieza fundamental del rompecabezas: el Inventario de la librería que poseía en su palacio del Puerto de Santa

marginales de su mano, como que traducía de otro modo el texto de Ausias. A este tenor, por haber parado en esta Librería gran parte de la que poesía Quevedo, hay en ella muchos tomos con su firma, y algunos con notas marginales».

${ }^{21}$ J. O. Crosby, En torno a la poesía de Quevedo, pág. 81.

22 H. Etthinghausen, op. cit., págs. 391-398.

23 Carta inédita de Maldonado a Crosby, 6 de mayo de 1966.

${ }^{24}$ Carta inédita de Maldonado a Crosby, 20 de mayo de 1966.

${ }_{25}$ H. Ettinghausen, op. cit., pág. 392, nota 1: «[...] and form telling me of the existence of a catalogue of the Monastery's library at the B. N., Madrid (MS. 1908). This is earlier (dated 1730) than the catalogue (dated 1788) at the Real Academia de la Historia, Madrid (MS. 9-10-1-2009), but the latter supplies date and place of printing for the books listed. The works by Seneca and Pindar mentioned p. 391, n. 1 and 4 adove, as well a number of other books which Quevedo is known to have possessed, appear in both catalogues, their dates and places of printing corresponding to those given in the later one. This lists three copies of Florus, the second of which may have been Quevedo's: 'Florij: De gestis Romanorum. Parisis 1542 et 1576. Yt. Antuerpiae 1584'».

${ }_{26}$ M. C. Álvarez Márquez, op. cit. 
María don Antonio Juan Luis de la Cerda, VII duque de Medinaceli27 con 1.474 partidas $^{28}$. Álvarez Márquez lo transcribe y confecciona a partir de él dos índices, uno de autores y obras seguras o probablemente identificadas y otro de autores y obras no identificadas o de difícil atribución, además de llevar a cabo un estudio en el que analiza diferentes asuntos, entre ellos la venta de la colección ${ }^{29}$ :

El fondo bibliográfico permaneció en el palacio del Puerto de Santa María hasta el día 4 de septiembre de 1731, en que, atendiendo una orden dada el 14 de julio del citado año por el nuevo titular de la Casa, don Nicolás Fernández de Córdoba, de la Cerda, Enríquez de Ribera, fue embalado en 42 cajones y transportado a Madrid en una recua de mulas, junto con los libros procedentes del palacio sevillano, ubicado en la collación de San Esteban y conocido con el nombre de «Casa de Pilatos», con la finalidad de formar en el Palacio de Lerma de la Corte y Villa una biblioteca centralizada.

Sin embargo, una vez en Madrid, el importante fondo bibliográfico procedente del palacio del Puerto, no permaneció muchos años en poder de la Casa de Medinaceli, sino que, como ha sucedido en otras ocasiones a lo largo de su historia, fue vendido, según una nota que aparece en la misma copia inventarial, a los frailes de San Martín de Madrid, poco antes de morir la duquesa de Cardona.

La venta se estipuló en «veinte y tantos mill reales de vellón», resultando muy ventajosa para los frailes, quienes obtuvieron más dinero con tan sólo la venta de los libros duplicados. Todo ello según consta en la citada nota, que dice así: «Esta librería se bendió poco antes de morir mi señora la duquesa de Cardona a los frayles de San Martín de Madrid en veinte y tantos mill reales de vellón y ellos sacaron más dinero sólo de los duplicados que vendieron».

Es difícil saber a qué duquesa de Cardona se refiere la nota. Es muy posible que se trate de doña Jerónima Spínola de la Cerda, Portocarrero y Aragón, esposa de don Nicolás, X duque de Medinaceli, muerta en 1757.

De todo esto se deduce que la biblioteca del duque hubo de ser vendida a los frailes de San Martín entre 1731 - fecha de traslado de la biblioteca del Puerto a Madrid- y 1757 - año de defunción de la duquesa de Cardona-. Aun podríamos ajustar más el término ad quem si tenemos en cuenta que la dedicatoria de Martín Sarmiento corresponde al año 1745, de manera que de los tres índices o alfabetos que manejamos de San Martín podrían ser descartados en el trabajo de reconstrucción de la biblioteca quevediana los fechados en los

27 «El inventario fue redactado el 23 de octubre de 1673 [...], ante el corregidor del Puerto, Juan Bautista de Valpuesta, y ante el escribano público, Pedro Baena, siendo llamado para que hiciese la tasación de los libros Francisco de Castro, librero avecindado en la citada ciudad». M. C. Álvarez Márquez, loc. cit., pág. 251.

${ }^{28}$ Véase M. C. Álvarez Márquez, loc. cit., pág. 252. Este es el mismo inventario al que hace referencia A. Paz y Meliá, op. cit., I. serie, págs. XXII-XXIII.

${ }^{29}$ M. C. Álvarez Márquez, loc. cit., págs. 259-260. 
años 1699 y 1730, quedando como único instrumento válido para la identificación y localización de los libros de la biblioteca del vil duque de Medinaceli - en la que se entremezclaron los volúmenes pertenecientes a Quevedoel más tardío de 1788.

Pero a pesar de que estos datos tengan apariencia de concluyentes, no se puede dar por zanjado el problema, puesto que hemos comprobado, como ya hizo Ettinghausen ${ }^{30}$, que en el índice de 1730 se incluyen entradas de libros en las cuales la información sobre autor y título coincide con las del índice de 1788 $\mathrm{y}$, a su vez, con la de algunos ejemplares localizados con firmas o anotaciones autógrafas de Quevedo, por lo que la incorporación del fondo del VII duque de Medinaceli al monasterio de San Martín se tuvo que producir en 1730 o incluso con anterioridad. Y hemos vuelto a cotejar simultáneamente con esos dos índices el del año 1699, y los registros bibliográficos sitúan los libros pertenecientes a Quevedo integrados en la colección del duque de Medinaceli en el monasterio de San Martín en las postrimerías del siglo XVII:

\section{Beuter, Pere Antoni}

Petri Antonij Beuter... Annotationes Decem ad Sacram Scripturam. Valentiae: per Ioannem Mey Flandrum, 1547.

Contenido: 1. De ordine librorum sanctorum apud Synagogam, \& Ecclesiam; 2. Qui libri sunt Canonici; 3. Quomodo Ecclesiam suscepit quos non susceperat Synagoga; 4. Quomodo Ecclesia mutauit ordinem Synagogae; 5. De libris desideratis; 6. De autoribus librorum Sanctorum; 7. De multiplici sensu Sacrae Scripturae; 8. De clauibus Sacrae Scripturae decem; 9. De translatoribus Sacrae Scripturae; 10. An vulgata editio sit Hieronymi.

Localización: BNE, R/369331.

En el interior de la cubierta, de mano de Quevedo: «Costó 30 Rs»; otra mano escribe la signatura topográfica y procedencia: «Cajón 6 San Martín», tachado: «C. 15». En este caso se puede afirmar con seguridad absoluta que procede de la biblioteca del monasterio de San Martín de Madrid, además nótese que la signatura tachada coincide con la que se le asigna al libro en el índice de 1730 (cajón 15).

\section{Repertorios:}

— Med. 1673 [73] $]^{32}$ : Ytten Bauter Anotaziones a la Sagrada Scriptura, vn tomo, en cuatro reales.

\footnotetext{
${ }^{30} \mathrm{H}$. Ettinghausen, op. cit.

${ }^{31}$ Eugenio Asensio se refirió a este libro de Quevedo en «El erasmismo y las corrientes espirituales afines», Revista de Filología Española, 36, 1952, págs. 31-99.

32 Recordemos que nos ha sido imposible la consulta del original o de una reproducción del inventario de Medinaceli del año 1673, por ello se cita a través del trabajo de M. C. Álvarez Márquez, op. cit., así pues, los dígitos entre paréntesis cuadrados — [73]— hacen referencia al número asignado por ella a la partida o ítem.
} 
- S. Martín 169933, fol. 73r: Petro Antonio Beuter 01 41; fol. 105r: cajón 41 Petri Antonij Beuter, annotationes in scrituram 01.

- S. Martín 173034, fol. 25r: Beuther (Petri Antonij) annotationes $10 \mathrm{ad} \mathrm{sac.}$ Scritpam qui lib. Sint canonic 115.

- S. Martín 178835, fol. 63v: Beuter (Petri Antonij) De ordine librorum Sanctorum apud Synagogam, et Ecclesiam. Valentiae. 1547.

ARMenINI, Giovanni Battista (ca. 1533-1609)

De'veri precetti della pittura di M. Gio Battista Armenini ... Ravenna: appresso Francesco Tebaldini, 1587.

Localización: Bibliothèque du Musée des Beaux-Arts de Budapest, ZZZB5183536.

\section{Repertorios:}

— Med. 1673 [676]: vn Tratado del Arte de la Pintura de Baptista Armenina, quatro reales.

- S. Martín 1730, fol. 12v: Armenini (Juan Baptista) preceptos de la pintura 1170.

- S. Martín 1788, fol. 31r: Armenini (Juan Bta.) De la Pintura en Ytno. 1587.

\section{ALIGHIERI, Dante (1265-1321)}

Dante con l'espositioni di Christoforo Landino et d'Alessandro Vellutello sopra la sua comedia dell' Inferno, del purgatorio et del Paradiso... In Venetia: apresso Giovani Battista Marchio Sessa et Fratelli (appresso gli heredi di Francesco Rampazetto), 1578.

Localización: University of Illinois, UNCAT $1578^{37}$.

Conserva múltiples anotaciones autógrafas de Francisco de Quevedo. En una hoja de guarda se lee la signatura topográfica del monasterio de San Martín: «Caj. 155».

${ }^{33}$ S. Martín 1699 tiene dos partes: 1.) Índice alfabético de autores y 2.) Índice topográfico o de signaturas topográficas; en primer lugar figura la información del índice de autores y en segundo lugar la del topográfico, separada la una de la otra por punto y coma. El primer grupo de dígitos señala el número de volúmenes que la biblioteca posee de ese autor (01), el último indica el número de cajón (41); sólo cuando se consulta el índice topográfico se accede al contenido de la signatura o cajón, es aquí donde se halla alguna referencia al título de la obra, sin precisar ningún otro dato que facilite la identificación de la edición.

${ }^{34}$ En S. Martín 1730 el primer dígito corresponde al número de tomos (1) y los siguientes al número de cajón (15). En muchas entradas de este repertorio se aprecia que los números de cajón han sido borrados y corregidos y en otras no constan.

${ }^{35}$ S. Martín 1788 modifica el sistema de signatura topográfica al sustituir cajón por estante. No se transcriben las cifras correspondientes al número de tomos y al estante por no aportar información que ayude a identificar los libros de la biblioteca del monasterio madrileño.

36 Véase P. Aström, «Un volume de la bibliothèque de Quevedo» ('Quevedo könyvtárából'), Bulletin du Musée National Hongrois des Beaux-Artes (A Magyar Nemzeti Múzeum Szépmuvézeti Múzeum Közleményei) (Budapest), 15, 1959, págs. 34-38.

37 Este ejemplar ha sido estudiado detalladamente por R. Cacho Casal, «Quevedo y su lectura de la Divina Commedia», Voz y Letra, IX/2, 1998, págs. 53-75. 


\section{Repertorios:}

—Med. 1673 [580]: Ytten Dante con la exposición de Cristóual Landino, vn tomo de a folio, en diez y seis reales.

- S. Martín 1699, fol. 23r: Dante [una mano distinta escribe en el margen izquierdo:] expurgado. [En la línea siguiente:] Item con Landino 01 159; fol. 157r: cajón 159 Dante con Christóval Landino.

- S. Martín 1730, fol. 67v: Dante Comedia del ynfierno, purgatorio y gloria en toscano con notas de Franco Sansobino. [En la siguiente línea:] Iten con Landino.

- S. Martín 1788, fol. 149r: Dante. El Ynfierno, el Purgatorio y el paraýso en verso. [En la siguiente línea] Ejusd con la exposición de Christoforo Landino en Ytalno. Venecia. 1578.

A estos descritos puedo añadir varios ejemplares localizados en la BNE que pertenecieron al monasterio de San Martín y también — posiblemente- a la biblioteca de Medinaceli, pues hallamos en el inventario del vII duque referencias a esas mismas obras:

\section{ARISTÓteles}

Poetica Aristotelis ab Antonio Riccobono latine conversa; eiusdem Riccoboni paraphrasis in poeticam Aristotelis; eiusdem ars comica ex Aristotele; cum indice copiosissimo. Patavii: apud Paulum Meietum, 1587.

Localización: BNE, 2/36115

En h. de guarda, signatura manuscrita del monasterio de San Martín: «C. 180». Repertorios: reales.

—Med. 1673 [1124]: Bicoboni [sic] sobre las poéticas de Aristóteles, seis - S. Martín 1699, fol. 9r: Antonio Rico-bono 01 112; fol. 132r: cajón 112, Antonius Rico-bonus Poetica Aristotelis

- S. Martín 1730, fol. 172v: Ricoboni (Antonij) Poetica Arist. In lati conversa 1204.

- S. Martín 1788, fol. 337v: Ricoboni (Antonii) In Poetican Aristotelis. Patavi. 1587.

\section{BOTERO, Giovanni (1543-1617)}

a) Della ragione di stato librii dieci con tre libri delle cause della grandezza delle città del sig. Giovanni Botero Benese... In Venetia: appresso i Gioliti, 1598.

Encuadernado con:

b) Aggiunte di Gio. Botero Benese alla sua ragion di stato nelle quli tratta dell' eccellenze de ali antichi capitani della neutralita, della riputatione, dell'agilità delle forze, della fortificationes. Con una relatione del mare. In Pavia, apresso Andrea Viani, 1598. [Le sigue, continuando la paginación, 
la Relatione del mare con la siguiente portada:] Relatione del mare di Giovanni Botero Benese. In Pavia, apresso Andrea Viani, 1598.

c) Modo d'usar il bossolo per pigliar piante de luoghi murati, e non murati... Aggiunta alla seconda parte della Ragion di stato del Signor Gio. Bottero, con le figure appropiate. In Milano, per Pandolfo Malatesta, impressore regio camarale, ad instanza di Pier Martire Locarni, e Girolamo Bordone, 1598.

d) Frachetta, Girolamo (1560-1620)

Il Prencipe di Girolamo Frachetta nel quale si considera il Prencipe \& quanto al gouerno dello Stato \& quanto al maneggio della guerra distinto in due libri... riueduto \& in molti luochi ampliato dall'autore medesimo. In Venetia, apresso Gio. Battista Ciotti, 1599. Dimensiones: 8 .

Localización: BNE, 3/29030

Signatura manuscrita del monasterio de San Martín en h. de guarda: «C. 176», tachado: «C. 214».

Repertorios:

Botero:

— Med. 1673 [711]: La razón del estado de Botero, un tomo en octabo, en dos reales.

- S. Martín 1699, fol. 48v: Joan Botero 02 137; fol. 147r: cajón 137: Juº Botero Relaciones y razón de estado 02.

- S. Martín 1730, fol. 33r): Botero (Juan) Razones de estado en toscano 1176.

- S. Martín 1788, 82r): Botero (Juan) De la razón de estado en italiano. Venecia. 1598.

\section{Frachetta:}

- Med. 1673 [655]: Seminario del gobierno de estado y guerra de Frageta [sic], un tomo de a folio, en catorce reales.

- S. Martín 1699, fol. 37v: Geronimo Francheta [sic] 01 141; fol. 148v: cajón 114: Gerónimo Francheta [sic] Gobierno de estado 01

- S. Martín 1730, fol. 85v: Francheta [sic] (Gerónimo) Seminario del gobierno de estado en toscano 1237.

- S. Martín 1788, 179r): Fracheta (Girolamo) Il seminario de governi di stato e di guerra. In Venecia, 1624.

El ejemplar de Frachetta descrito en Med. 1673 tiene formato folio, por tanto, es necesario destacar que la partida [655] no puede referirse al volumen hallado. Sin embargo el ítem del inventario de la librería del duque [711] concuerda perfectamente con la obra que actualmente custodia la BNE; también ha de observarse que tanto en S. Martín 1699 como en S. Martín 1730 se registran ambas obras, la de Botero y la de Frachetta, mientras que en S. Martín 1788 sólo figura la de Botero y no la de Frachetta impresa en Venecia, 1599.

Por otro lado, S. Martín 1788, fol. 179r registra una edición más de la obra de Frachetta: «Il seminario de governi di stato e di guerra. In Venetia, 1624», que 
ha de ser Il seminario de gouerni di stato et di guerra di Girolamo Frachetta... cauati da diuersi scrittori politici et di cose di guerra con un discorso sopra ciascun di detti capi. Et in questa terza impressione dall'autore medesimo riueduto \& in molti luoghi ampliato. In Venetia: per Euangelista Deuchino, 1624. Esta última edición tiene tamaño folio, y es probablemente a la que hace referencia Med. 1673 [655].

Como hemos podido comprobar, todos los libros mencionados figuran en el repertorio de Medinaceli y en los tres de San Martín, excepto la obra de Armenini que no hallamos en S. Martín 1699. Todo esto conduce a pensar que el fondo bibliográfico del Puerto de Santa María del VII duque de Medinaceli ingresa en el monasterio benedictino de Madrid en fechas anteriores a las apuntadas por Paz y Meliá y Álvarez Márquez, como ya señalaron Ettinghausen, Crosby y Maldonado. Aun así, se podría argumentar que con posterioridad a las fechas que figuran en la portada de cada índice se fueron insertaron referencias bibliográficas, aunque las más de 1.400 partidas del inventario de Med. 1673 resultan ser muy numerosas a la hora de encontrar espacios libres para incorporarse a los inventarios de la librería madrileña sin dificultades. Mas aceptando que se hayan intercalado las 1.471 partidas después de 1731, ¿por qué se insertaron también en el índice de 1699? Por algunas anotaciones que se conservan en S. Martín 1699 podemos suponer que este inventario se siguió utilizando después de 1730, por ejemplo, en el fol. 69r se advierte, en una de las entradas, con una nota marginal: «Prohibido está con los demás en el Archivo a donde se pasaron para mexor seguridad y custodia. En 8 de marzo de 1769 y tamb $^{\mathrm{n}}$ los manuscriptos y lithúrgicos». Esta apostilla pone de manifiesto que setenta años después de la datación que figura en su portada - y ya confeccionado el índice de libros fechado en 1730 - los monjes benedictinos seguían empleando ese primer repertorio.

Sin duda, se ha de buscar una explicación que nos permita hacer compatibles las fechas de traslado (1731) y posterior venta (?) de la librería de Medinaceli con las de redacción de los índices de S. Martín 1699 y 1730 . Que algunos libros apostillados y firmados por Quevedo se trasladaron junto con los del duque, primero a Sevilla y después a Sanlúcar, no se pone en tela de juicio, ya que el conocido testimonio aportado por Nicolás Antonio así lo confirma ${ }^{38}$ :

En este año de 1647 truxeron a Seuilla cantidad de libros i papeles que dexó D. Fran ${ }^{\mathrm{co}}$ de Queuedo así de los compuestos por él mismo como de otros que auía recogido con curiosidad. Lleuábanse estos papeles al duque de Medina Celi a Sanlúcar i antes que saliesen de Seu. tuue lugar de uerlos por merced que me hiço D. Juan de Arroio [...]. Entre los demás auía un libro de letra todo de Juan Vázquez del Mármol i en él recogidos y encuadernados diuersos papeles de antigüedad [...].

\footnotetext{
${ }^{38}$ En el BNE, ms. 7365, fol. 281r, Papeles y opúsculos de Nicolás Antonio.
} 
Pero resulta necesario a todas luce s revisar de nuevo los papeles que conserven archivo y biblioteca de la casa ducal relacionados con la colección del VII duque de Medinaceli a causa de las inconsistencias señaladas ${ }^{39}$, y continuar con la búsqueda de la documentación correspondiente al monasterio madrileño con el fin de localizar la información derivada de la operación de transacción del fondo de Medinacelite.

Lo que parece definitivo es que no se deben de descartar en el proceso de reconstrucción de la biblioteca hipotética de Quevedo ninguno de los tres índices del monasterio, los dos primeros son muy útiles por el sistema de signatura topográfica utilizada (número de cajón) y el tercero por registrar fecha y lugar de impresión; además no se han de considerar baladí los datos sobre las dimensiones de los volúmenes que varios de estos repertorios aportan, ya que en ocasiones se convierten en complemento imprescindible para discriminar entre posibles ediciones postuladas a tener un hueco entre los libros del autor o incrementar las propuestas. Podemos tomar de ejemplo el ítem de Quev. 1646 [18/11]: «Un bocabulario de a fo. en seis reales», en esta ocasión no puede discutirse que la abreviatura fo es equivalente a folio, con este dato como punto de partida

${ }^{39}$ Actualmente es compleja la consulta del archivo de la casa ducal, dividido entre Sevilla y Toledo, a causa del litigio en el que se ve inmerso desde hace años (véase Fundación casa ducal Medinaceli, «El archivo», Sevilla: Fundación casa ducal Medinaceli, <http://www. fundacionmedinaceli.org/archivo/ficha.aspx?id=16052> [consulta: 16 de febrero de 2015]). Esta situación ha impedido que podamos revisar los documentos a los que hacen referencia A. Paz y Meliá, op. cit., y M. C. Álvarez Márquez, op. cit.

${ }^{40} \mathrm{El}$ Libro de actas de los PP. del Consejo de este monasterio de San Martín de Madrid, que antes estaba dividido en dos. Comprende los años desde 1659 a 1782 y consta de 443 folios (BNE, ms. 13284) da cuenta de diversas adquisiciones de libros y de otros asuntos relacionados con la biblioteca, tal es el caso de la compra de la librería de don Jerónimo Jiménez por tres mil ducados el cinco de agosto de 1698, un año antes de la redacción del primer índice que manejamos, fol. 155r: «[...] propuso su $\mathrm{P}^{\mathrm{d}}$ que por quanto se vendía vna librería grande la qual quedó por fin y muerte de d. Jerónimo Jiménez y se vende de orden de don Jerónimo digo d. Joan de Ocampo y hauiéndose tasado por los libreros de esta corte la dieron de valor noventa mill treçientos y setenta y seis reales de $\mathrm{v}^{\mathrm{n}} \mathrm{y}$ hauiéndose visto por diferentes veçes los libros $\mathrm{y}$ autores de que se compone la dicha librería así por su $\mathrm{P}^{\mathrm{d}}$ como por nro. $\mathrm{P}^{\mathrm{e}}$ el $\mathrm{M}^{\mathrm{o}}$. fr. Joan Bautista Landito, quien embió la lista de ellos conformes rrespondieron que si daban dicha librería en tres mill ducados hacía una gran compra qualquiera que entrase en ella en conformidad de lo qual lo enpezó a tratar su Pd con el dicho D. Joan de Ocampo y después de largas conferencias se convinieron y axustaron en que dándole los dichos tres mill ducados alargaría y dicha librería y propuesto todo esto en la conformidad de su contenido a sus $R^{\text {mos }} \mathrm{P}^{\text {des }} \mathrm{y}$ votándose por auas blancas y negras todos vinieron en que no se perdiese este lançe y que se comprase la dicha librería y así fueron conformes los votos». No es esta la única nota sobre los libros del monasterio que se recoge en este Libro de actas, el 11 de septiembre de 1733, fol. 306r y v: «propuso su $\mathrm{P}^{\mathrm{d}}$ como un librero desta corte quería dar por los cinco tomos de Bollando los Anales de Mavillón en que no convinieron dhos Padres del Consejo»; otra nota sobre la librería del monasterio se registra en el acta del día 27 de febrero de 1735, fol. 311v. En ninguno de sus folios se menciona la adquisición de la biblioteca del duque de Medinaceli. Por tanto, en este rompecabezas aún se echan en falta algunos documentos que no descartamos puedan aparecer en un futuro; hemos iniciado su búsqueda sin obtener hasta ahora resultados, aunque aún no han sido agotadas todas las posibilidades. 
veamos las propuestas barajadas para la identificación de la obra registrada en esta partida. En opinión de Maldonado41:

Los más probables parecen ser el de Alfonso Fernández de Palencia y el de Nebrija, ambos figuran en el Índice [S. Martín 1788], sin referencias tipográficas; pero no cabe desechar la posibilidad de que sea el Vocabulario eclesiástico de Rodrigo Fernández de Santaella, tantas veces reimpreso dese 1499. En Series ${ }^{42}$, t. II, pp. 10 y 19, hay noticia de un ejemplar del Vocabulario de Fernández Palencia.

El inventario realizado de la librería de don Antonio Juan Luis de la Cerda del Puerto de Santa María es vital, aquí hallamos varias obras descritas con el término «vocabulario», ninguna de ellas puede hacer referencia al Vocabulario de Fernández de Palencia, así pues, sin descartarlo de forma definitiva, podemos relegarlo a un imaginario apartado de menos probables:

- Med. 1673 [560]: Bocabulario del Derecho, vn tomo en cuarto, en seis reales.

- Med. 1673 [581]: Bocabulario ytaliano, vn tomo de marquilla, en veinte reales.

- Med. 1673 [1026]: Bocabulario de Antonio, vn tomo de a folio, en treinta reales.

- Med. 1673 [1137]: Bocabulario latino, griego y francés, vn tomo en quarto, veinte reales.

- Med. 1673 [1413]: Bocabulrio ytaliano y castellano, vn tomo en quarto, en diez y ocho reales. reales.

De los seis ítems podemos rechazar los números [560, 581, 1137 y 1413] por ser estos de dimensiones diferentes al folio. Por tanto, el libro de Quev. 1646 podría ser el Vocabulario de Nebrija o el de Fernández de Santaella [1026 y 1450?], ambas obras descritas en los índices de San Martín ${ }^{43}$ :

- S. Martín 1730, fol. 142v: Nebrija (Antonij) [...] Eiusdem Vocabularium hisp. lat. en un cuerpo 2-19[.].

- S. Martín 1788, fol. 288r: Nebrisensis (Antonij) [...] Ejud. Vocabularium.

S. Martín 1788 excepcionalmente no informa sobre el lugar y año de impresión, por lo que el ejemplar de la obra de Nebrija de esa biblioteca pudiese carecer de portada. Atendiendo a los pocos datos que tenemos localizamos

${ }^{41}$ F. R. C. Maldonado, op. cit., pág. 421. Fernández y Simões repiten una a una las propuestas de Maldonado sin aportar ningún dato nuevo que ayude a concretar este ítem de Quev. 1646.

${ }^{42}$ Se refiere a la obra de A. Paz y Meliá, op. cit., II. serie.

${ }^{43}$ En S. Martín 1699 son cuatro las obras de Nebrija que se describen, ninguna de ellas es el Vocabulario. Nótese que ni S. Martín 1730 ni 1788 ofrecen los datos tipográficos del volumen, hecho que ya señaló Maldonado, por lo que es probable que el libro careciese de ellos. 
alguna edición posible ${ }^{44}$, todas ellas en folio, del Diccionario de romance en latín: «En Grnada [i.e. Granada]: en casa de Antonio de Nebrissa, 1589»; «En Seuilla: por Alonso Rodriguez Gamarra: de consentimiento de don Augustin Antonio de Nebrissa..., 1610»; junto a estas, hay un «[Bocabulario de Antonio de Nebrija...]. [s. 1.: s. n., s. a.] Tít. y autor tomados de privilegio. Fecha de fe de erratas: 1638». Dimensiones en folio ${ }^{45}$. Rechazamos por haberse impreso en 4. la de «Hispali: in domo Ioannis Varele salmanticensis, 1516».

Respecto a la obra de Fernández de Santaella, observamos que no está presente en S. Martín 1699 y que se ha insertado en tiempo posterior a la redacción del catálogo en S. Martín 1730, asignando al libro ya una signatura de estante más número, lo que significa que la biblioteca había abandonado el sistema de cajón cuando éste ingresa en la biblioteca, por lo que pudo adquirirse tras la colección de Medinaceli:

- San Martín 1730, fol. 207v: [se inserta entre dos entradas, con mano diferente:] Vocabo ecco. [sobre la línea:] [estante:] 54 n. 3

- San Martín 1788, fol. 408r: Vocabularium Ecclesiasticum a Roderico Ferdinando de Santaella. Cesaraugustae, 1540 [estante:] 54 [número:] 6.

De los 25 registros bibliográficos que de esta obra tiene el CCPBE solo 10 se editaron en folio, de los libros aquí descritos carecen de portada dos, la información tipográfica o pies de imprenta de los restantes es la que sigue: 1) «Hispali: Johannes [Pegnitzer]. Magnus [Herbst] et Thomas [Glockner] (14 febrero, 1499)»; 2) «Compluti : apud Michaelem de Eguía, 1529 (1527)»; 3) «Toleti : Per Ioannem de Ayala, 1556; 4) Toleti : in aedibus Ioannis Ferrarij, impensis Ludouici Gutierez [sic] Bibliopolae complutensis, 1552»; 5) «Salmanticae: apud Andream de Portonariis, 1549, calendis Maiis»; 6) «Compluti: apud Ioannem Brocarium, 1540 (1539, mense decembri)»; 7) «Compluti: apud Michaelem de Eguia, 1529», y 8) «Cesarauguste: arte, industria simul \& expensis Georgij Coci Theutonici,1523, 11 Kal. Maij».

Como hemos podido comprobar, la combinación de los índices de San Martín más los inventarios de Quevedo y Medinaceli ofrece un conjunto de datos que facilitan la identificación de las obras reseñadas y nos acercan a la posterior localización de los ejemplares que formaron parte de la biblioteca hipotética de Quevedo.

No es de menor relevancia cuestionarnos cuándo Quevedo pudo acceder a ese conjunto de libros descritos en Quev. 1646. Los enumerados en esos inventarios de los bienes de Quevedo muy probablemente no fueron consultados

${ }_{44}$ Todas las referencias de las ediciones de la obras de Nebrija y de la de Fernández de Santaella proceden de Catálogo colectivo de patrimonio bibliográfico español [en línea]. Madrid: Ministerio de Educación Cultura y Deporte, $<$ http://ccpb_opac.mcu.es/cgi-brs/CCPB/ abnetopac/O9088/ID29ce20c0/NT1?ACC=101>, login: 'ccpb' [consulta: 26 de febrero de 2015], lo abreviamos: $C C P B E$.

${ }^{45}$ La descripción pertenece al ejemplar propiedad de la Biblioteca Diocesana de Córdoba, con signatura CO-BD, 17/R.006.781/1, falto de portada. 
por el escritor después de diciembre del año 1639, quizás en los breves periodos que pasó en la corte después de ser excarcelado en 1643. Por el epistolario del escritor sabemos que parte de sus bienes, tras el penoso periodo de San Marcos de León, fueron custodiados por algunos de sus conocidos, amigos o allegados, y que varios de sus enseres se reclamaron tras su puesta en libertad, entre los que no constan los libros, al menos en las cartas conservadas. Todos aquellos objetos que figuran en esos los inventarios de bienes fechados en 1646 no viajaron con Quevedo a la Torre de Juan Abad, donde transcurren los últimos momentos de su vida. Por tanto, en las casas de Francisco de Oviedo ${ }^{46}$ : cien ítems hallamos en el inventario que corresponden a más del centenar de libros; Juan de Molina: 50 ítems que corresponden a otros tantos títulos, y el canónigo Guerrero: 37 entradas para igual número de obras. Esta cuestión de carácter cronológico, no planteada hasta ahora, se ha de tener en cuenta, pues en la redacción o revisión de los escritos de esa última etapa Quevedo no tuvo oportunidad de consultar los libros que dejó en depósito en Madrid ${ }^{47}$. Por tanto, este dato pasa a ser un elemento más en el proceso de datación de la obra quevediana. Sobre el conjunto restante, propiedad de Medinaceli, podemos pensar que durante los periodos madrileños en los que el poeta se alojaba en la casa del duque, sin descartar la posibilidad de que a su vez tomase libros de su colección en préstamo.

${ }^{46} \mathrm{El}$ arca junto a los dos baúles que a la muerte de Quevedo se hallaban en casa de Francisco de Oviedo han de ser los mismos que junto a una cama - también en casa de Oviedo según consta en el inventario- antes custodió Juan de Espinosa, agente del duque de Medinaceli, y que Quevedo solicita por carta a Oviedo que recupere tras la muerte de Espinosa: «Mire v. m. por donde ha querido Dios que yo le vuelva a ensuciar la casa con mis trastos. Hago saber a v. m. que dejé en casa de Juan de Espinosa dos baúles y un arca de libros y papeles, de precio y estimación, el uno cuadrado de baqueta con dos cerraduras, el otro de baqueta viejo, con otras dos cerraduras de tapa comba, y largo: la arca, clavada la cerradura por falta de llave»; sobre el mismo asunto escribió Quevedo a la viuda de Espinosa: «Ahí dejé embarazando a v. m. el desván dos baúles y una arca, clavada la cerradura, que conoce bien la madre de Juan. Suplico a v. m. se sirva de mandar que se entreguen a la persona que el señor don Francisco de Oviedo ordenare, por cuya mano envío a v. m. este pésame, que su excelencia me da gran prisa que me vaya a convalecer a Sanlúcar, y me es fuerza llevarlos conmigo» (F. de Quevedo, Epistolario, ed. de L. Astrana Marín, Instituto Editorial Reus, Madrid, 1946, págs. 156 y 157). En el testamento de Quevedo se menciona un baúl heredado por el VII duque, de cuyo contenido todo lo ignoramos, que bien pudo guardar, papeles, cartas y libros: «Item, mando que un baúl cerrado que tengo en la Villa de La Torre de Juan Abad, en la sala de las casas, que tengo en ella debajo de la ventan [sic], a el cierzo, se dé como está a su excelencia el duque de Medinaceli y Alcalá; y encargo a mis albaceas lo remitan luego, porque esta es mi voluntad» (citamos por J. O. Crosby y P. Jauralde, Quevedo y su familia, Universidad Autónoma de Madrid, 1992, pág. 355).

${ }^{47}$ Sabemos que tuvo acceso a diversas ediciones de algunos textos; así ha demostrado F. Moya del Baño (Quevedo y sus ediciones de textos clásicos. Las citas grecolatinas y la biblioteca clásica de Quevedo, Universidad de Murcia, 2014, págs. 28-32), que Quevedo empleó varias ediciones de una misma obra, además de poner de manifiesto que no siempre cita por las ediciones registradas en S. Martín 1788; véanse además las págs. 440-441, donde reseña, por ejemplo, las diferentes ediciones que utilizó de Cayo Petronio Árbitro, Satiricón, y de Píndaro, Odas. 
También hemos de poner en duda que todos los libros registrados en el inventario de $\mathrm{Med}$. 1673 se vendiesen al monasterio madrileño. En principio las sospechas se fundan en una reproducción publicada en las Series de Paz y Meliá de la portada de un impreso de Bonatti, en la que Quevedo dejó dos firmas y rúbricas ${ }^{48}$ :

\section{BonatTI, Guido}

Guido Bonatus de Forliuio decen Continens Tractatus Astronomie. Venetijs: mandato [et] expensis Melchionis Sesse: per Iacobum Pe[n]tium Leuce[n] sem, 3 julio 1506.

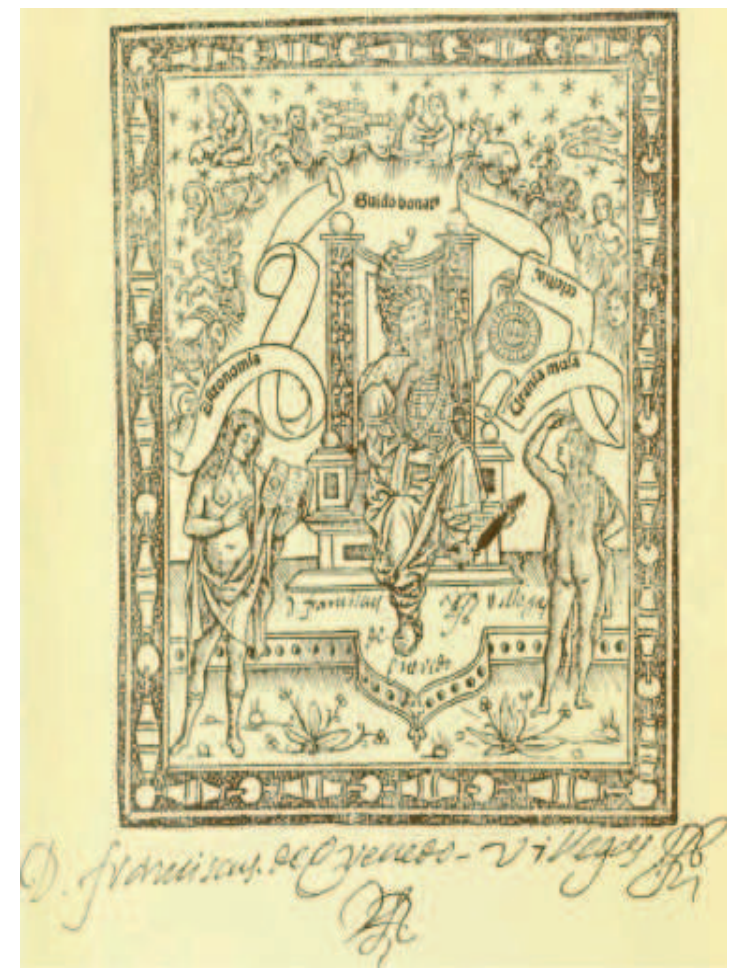

48 A. Paz y Meliá, op. cit., I. serie, ilustración 29, afirma conocer solo un libro con autógrafo de Quevedo en la biblioteca de Medinaceli, del que reproduce la página de portada en la que se lee perfectamente la firma de Francisco de Quevedo en dos ocasiones, una dentro de lo que creemos un grabado y otra en la parte inferior de la página. En el pie de la lámina, señala que se trata de la edición de Venecia: J. P Leucense, 1506. Los datos de impresión han sido tomados del ejemplar que se halla en la BNE, signatura R/19956, en el que figura una nota manuscrita en portada: «Petri Gothmani Cordvbensis». 


\section{Sin localizar ${ }^{49}$}

\section{Repertorio:}

- Med. 1673: [898] Guido Bonato De Astronomia, vn tomo en en [sic] folio, en cuarenta reales.

Ni en el repertorio de S. Martín 1699 ni en el de S. Martín 1730 figura obra alguna de Guido Bonatti, tampoco en el alfabeto $S$. Martín 1788 consta la obra reseñada en líneas anteriores. No obstante, encontramos en este último un asiento bibliográfico de este autor (fol. 77r): «Bonati (Guidomi) De Astronomia. Basileae, 1550» que como puede comprobarse no se corresponde con la obra en la que Quevedo plasmó sus firmas y rúbricas. Álvarez Márquez ${ }^{50}$ también asigna la partida 900 a Bonatti, por lo que el inventario de $\mathrm{Med}$. 1673 registra otro título más de este autor: «Ytten Guido Baldo De Astronomía, dos tomos de a folio, quarenta reales».

La edición que describe S. Martín 1788, identificada hace años por Mantinengo ${ }^{51}$, es la siguiente: Guidonis Bonati... De astronomia tractatus X: vniuersum quod ad iudiciariam rationem Natiuitatum, Aëris, Tempestatum, attiner, comprehendentes; adiectus est Cl. Ptolemaei liber fructus, cum commentarijs Georgij Trapezuntij. Basileae: [Jacob Parcus], 1550. Posiblemente la misma que anteriormente se describió en la partida 900 del repertorio de Medinaceli. De esta obra la BNE conserva un ejemplar (R. 14812) con notas manuscritas que parecen pertenecer a dos manos diferentes, quizás una de ellas a Quevedo ${ }^{52}$.

No parece posible que el ejemplar de Bonatti firmado por Quevedo sea el único libro de la biblioteca del VII duque de Medinaceli que no se vendiese a los

49 Por A. Paz y Meliá sabemos que este libro podía consultarse en el Archivo y Biblioteca del duque de Medinaceli en 1915 (véase nota anterior). Lo sitúa en la misma colección Astrana Marín más de quince años después. Véase L. Astrana Marín, «Modo de escribir de Quevedo: su especial puntuación y ortografía», en Francisco de Quevedo, Obras completas. Verso, Aguilar, Madrid, 1932, pág. 1181. Hace unos años, desde el Archivo y Biblioteca de la Casa Ducal de Medinaceli, Casa de Pilatos de Sevilla, nos confirmaron que dicho ejemplar no se hallaba allí, también hemos comprobado que no fue adquirido en los años 60 del pasado siglo por Bartolomé March, quien adquirió un buen conjunto de libros pertenecientes a esta casa nobiliaria; por tanto, hoy lo consideramos en paradero desconocido.

${ }^{50}$ M. C. Álvarez Márquez, op. cit., pág. 315.

${ }^{51}$ A. Martinengo, La Astrología en la obra de Quevedo, Alhambra, Madrid, 1983, págs. 174-175.

52 Hallamos abundantes notas manuscritas en la primera parte de la obra, son considerablemente menores en número y extensión en la segunda, tercera y cuarta, inexistentes en la quinta y tan solo leemos una en la sexta y en el texto final de Ptolomeo (columna 27). Hemos comparado las anotaciones manuscritas del ejemplar de Bonatti (véanse sobre todo las apostillas de las columnas 10, 15, 21, 49, 95, 189, 386, 477, 646 y 647) con las que se hallan en el impreso de Eliano (BNE, R. 9560) y pueden apreciarse algunas similitudes entre ellas. No obstante, este ejemplar precisa de un estudio caligráfico en detalle que se ha acometido junto a las apostillas manuscritas de otros ejemplares susceptibles de pertenecer a la mano de Quevedo. Para el ejemplar de Eliano véase el estudio realizado por L. Schwartz e I. Pérez Cuenca, «Unas notas autógrafas de Quevedo en un libro desconocido de su biblioteca», Boletín de la Real Academia Española, LXXIX, 1999, págs. 67-91. 
monjes benedictinos, pues se observa que no todos los títulos y autores que se registran en el inventario de Med. 1673 se hallan en los catálogos de S. Martín 1699, 1730 y 1788, este es el caso de las obras de Bartolomé de las Casas:

- Med. 1673 [1103]: Ymperio soberano por el Obispo Don fray Bartholomé de las Cassas, vn tomo en quarto, en ocho reales.

- Med. 1673 [1131]: Controbersa del Obispo fray Bartolomé de las Cassas, tomo en quarto, ocho reales.

El primer ítem ha de corresponder a:

Tratado comprobatorio del Imperio soberano y principado vniuersal que los Reyes de Castilla y León tienen sobre las Indias compuesto por... Bartholomé $d[e]$ las Casas o Casaus de la orden d[e] Sancto Domingo... Fue impressa... en... Seuilla: en casa d[e] Sebastián Trugillo, 1552 (1553).

De esta edición conserva un ejemplar la Fundación Bartolomé March que bien podría ser el mismo que encontramos en Med. 167353. La segunda obra:

Aqui se contiene vna disputa o controuersia entre ... fray Bartholomé de las Casas o Casaus ... y el doctor Ginés de Sepulueda... sobre que el doctor contendía que las conquistas de las Indias contra los indios eran lícitas, y el obispo... defendio y affirmó auer sido y ser ipossible [sic] no serlo, tiránicas, injustas [e] iniquas... En Seuilla: en casa de Sebastián Trugillo..., 1552.

Como decía, ninguna de estas obras se encuentra en los repertorios consultados de San Martín. Igual podría ocurrir con la obra Dictionarium medicum, vel, expositiones vocum medicinalium ad verbum excerptae ex Hippocrate, Aretaeo, Galeno... cum latina interpretatione... de Henri Estienne, que Alvarez Márquez ${ }^{54}$ identifica con la partida de Med. 1673 [942]: «Diçionario médico, tomo en quarto, quatro reales». En los repertorios del monasterio madrileño se describen varias obras de Estienne, pero ninguna de ellas corresponde a la mencionada ${ }^{55}$.

Conocemos otros catálogos manuscritos de la biblioteca de Medinaceli, entre ellos, uno fechado en el año 1759 de obras griegas y latinas ${ }^{56}$, y no hemos de

${ }^{53}$ Biblioteca de la Fundación Bartolomé March, signatura: 460315. No hemos podido comprobar si esta obra figura en los índices de Med. 1759, ni tampoco si el libro conserva alguna marca que lo relacione con la colección ducal.

${ }_{54}^{54}$. C. Álvarez Márquez, op. cit., pág. 289.

${ }_{55}$ S. Martín 1699, fol. 45v: «Cajón 134 Stephani Thesaurus linguae Graecae 04»; S. Martín 1730, fol. 192r: «Stephani (Henrici) Economia virtutis grec lat ex grecis poesis 1227 /item Biblia ebrea Parisis [...]/eiusdem note in apianus de bellis romanorum vide Apiam/Eiusdem prefacijs hest' Herodiani de rom Imperio/Eiusdem thesaur' grece linguae item glosariam/Eiusdem emporij Franfordiense vide Nicolais reusneris/Eiusdem fracmenta novem poetaron/Eiusdem Carmina Pindara [...]»; S. Martín 1788 fol. 373v: «Stephani (Henrici) Thesaurus Graecae. Linguae. 1572», en la línea siguiente: «Ejusd: Glossarium. 1573».

${ }^{56}$ Index alphabeticus librorum eruditorum criticorum et miscelaneorum latine et graece, ex Bibliotheca Ex ${ }^{m i}$. D. D. Ducis a Metimna Coeli, factus anno 1759, de la Biblioteca de la Fundación Bartolomé March, en Palma de Mallorca, signatura: ms. 13/8/7. Nos referiremos a él con la abreviatura Med. 1759. En el primer folio del ms. se explica que las obras en él 
suponer que no se describan en él alguno de los libros que pertenecieron al vII duque de Medinaceli —o a Quevedo-. Por ejemplo, de las cuatro obras que se registran en el repertorio de Med. 1673 del autor italiano Leonardo Fioravanti solo una se empareja con un registro bibliográfico del índice del monasterio:

\section{FioraVANTI, Leonardo}

1) Med. 1673 [634]: Secretos raçionales de Florabanti, vn tomo en octabo, en tres reales.

2) Med. 1673 [635]: Caprichos medizinales de Florabanti, en dos reales.

3) Med. 1673 [636]: Espejo de ziençia vnibersal de Florabanti, en dos reales.

4) Med. 1673 [640]: Física de Fioravanti, vn tomo en octabo, en quatro reales.

Quizá las tres primeras referencias correspondan a las siguientes obras: 1) Del compendio de i secreti rationali, dell'eccell. medico \& cirugico $m$. Leonardo Fiorauanti bolognese, libri cinque ... Con la tauola di tutti i capitoli, las impresiones en $8^{\circ}$. de esta obra son muchas y la insuficiencia de datos impide determinar la edición concreta que formó parte de la colección ducal ${ }^{57}$. 2) De capricci medicinali..., en este caso desconocemos incluso el tamaño del libro, por tanto, nos resulta difícil avanzar más allá del título. La siguiente obra de Fioravanti, 3) Dello specchio di scientia uniuersale..., como las anteriores, conoció varias impresiones $^{58}$. Ninguna de las tres obras de Fioravanti mencionadas figuran en los repertorios de S. Martín 1699, 1730, 1788 y una de ellas, Dello specchio di scientia se halla descrita en el de Med. 1759.

- Med. 1759: Fioravanti, Leonardi, espexo de la ciencia, en ytaliano, Venecia, año de $1567 . . .1$...Per...8 2 [1 tomo, encuadernado en pergamino, en 8 ., estante 2].

La reseñada en este último inventario tiene que ser la edición Dello specchio di scientia vniversale dell 'eccellente medico \& cirugico M. Leonardi Fiorauanti..., libri tre. Nuouamente ristampato, con molte cose agionte. In Venetia: appresso Andrea Rauenoldo, 1567.

registradas pertenecen a los estantes números 70, 72 y 73 . Las signaturas topográficas para estos libros se constituyen por los números correspondientes al estante, figuran al lado de los datos bibliográficos de la obra descrita; es habitual que cada entrada contenga: nombre de autor, título, lugar y año de impresión, número de tomos, encuadernación y tamaño. Hemos podido comprobar que muchos de los libros aquí registrados se encuentran en la biblioteca de la mencionada fundación.

${ }^{57}$ Algunas de las ediciones localizadas fueron impresas en Venetia: appresso Vincenzo Valgrisi, 1564; Venetia: appresso Andrea Rauenoldo, 1566; Venetia: appresso gli heredi di Melchior Sessa, 1571; Turino, appresso Gio. Dominico Tarino, 1592; Vinegia: presso Altobello Salicaro, 1596.

58 De esta obra se han localizado las siguientes: a) In Venetia: Vincenzo Valgrisii, 1564; b) In Venetia: appresso Andrea Rauenoldo, 1567; c) In Venetia: Appresso gli Heredi di Marchiò Sessa, 1572; d) In Venetia: apresso gli Heredi di Melchior Sessa, 1581; e) In Venetia: appresso gli heredi di Marchiò Sessa, 1583; f) In Venetia: appresso Lucio Spineda,1603; g) In Venetia: per il Valentini, 1624, y h) Venetia: appresso Zaccaria Conzatti, 1660. 
El inventario de Med. 1673, como se indicó, describe una cuarta obra del médico italiano reseñada en $S$. Martín 1730 y 1788 , por lo que probablemente de las cuatro obras de Fioravanti que poseyó el VII duque solamente la de la partida 640 fue a parar a manos de los monjes benedictinos:

- S. Martín 1730, fol. 84r: Fiorabanti (Leonardo) de Medicina 1 [sin signatura].

- S. Martín 1788, fol. 176r: Fiobrabanti [sic] (Leonardo) Phisica en ytaliano. Venecia, 1629.

Se trata de la edición Della fisica dell'eccellente dottore \& caualiero M. Leonardo Fiorauanti bolognese, diuisa in libri quattro... Di nuouo ristampata con la tauola de' capitoli. In Venetia: per il Spineda, 1629. De esta impresión posee un ejemplar la BNE (signatura 3/76931), que tiene en una hoja de guarda la signatura manuscrita «C. 189», por tanto, se trata del mismo libro que poseyó el monasterio de San Martín, cuya probable procedencia sea la biblioteca del duque de Medinaceli, aunque no podemos adjudicárselo al fondo de Quevedo por no encontrar en el ejemplar rastro alguno de su mano.

La biblioteca ducal contó entre sus libros con otra obra de Fioravanti ahora en de la Fundación Bartolomé March ${ }^{59}$, aunque existe la posibilidad de que no proceda de la colección de Antonio Juan Luis de la Cerda, puesto que no se encuentra en el inventario de su biblioteca.

Tras un primer análisis del inventario de Med. 1673 observamos que Antonio Juan Luis de la Cerda reunió un buen conjunto de obras de un nutrido número de autores en las más diversas lenguas, aunque predominan en él las escritas en latín y español ${ }^{60}$, pero también se detectan notables ausencias, tan significativas a la hora de valorar su biblioteca como las presencias ${ }^{61}$. Una de esas notables ausencias es la de Justo Lipsio ${ }^{62}$, tanto en los inventarios de Quevedo como en el de Medinaceli no hay entrada que pueda asignarse al humanista flamenco. Si es cierto que la relación del duque y del escritor se acercó al plano intelectual y el primero fue aconsejado en sus lecturas y orientado en la adquisición de libros por el segundo, parece improbable que entre las recomendaciones de don Francisco no figurase alguna obra de Lipsio ${ }^{63}$.

${ }^{59}$ Del regimiento della peste dell' eccelente medico et cirugico M. Leonardo Fioravanti... In Venetia: apresso Andrea Revenoldo, 1565. Conserva los exlibris del duque de Medinaceli y Santisteban y de Bartolomé March (Biblioteca Fundación Bartolomé March, signatura: 910603).

${ }^{60}$ M. C. Álvarez Márquez, op. cit., págs. 252, 254-259.

${ }^{61}$ Véase V. Infantes, «Las ausencias en los inventarios de libros y de bibliotecas», Bulletin Hispanique, 99, 1997, págs. 287 y sigs.

${ }^{62}$ En los inventarios de bienes de Quevedo publicados por F. R. C. Maldonado, op. cit., tampoco hallamos obra alguna del humanista flamenco.

${ }^{63}$ En carta sin fecha escribe Quevedo al duque de Medinaceli para tratar, entre otros asuntos, de una serie de libros que reúne para él: «Yo voy ya juntando libros a vuecelencia; y si puedo asir unos que ha querido comprar Julio para el Almirante, será buena ocasión. Descanse vuecelencia, que en lo que me mandare procuraré se conozca que es don Francisco de Quevedo quien sirve a vuecelencia», en otros momentos menciona de nuevo las gestiones 
Es preciso apuntar que las obras de Lipsio que registra el índice de S. Martín 1788 no se incluyen en el inventario de Med. 1673, así pues, la lógica conclusión ha de ser que la procedencia de esos ejemplares es otra ${ }^{64}$. Pero lo cierto es que de la misma manera que se ha comprobado que no todos los libros que se describen en el inventario de Med. 1673 se hallan en los catálogos de San Martín consultados - el monasterio quizás vendió algunos de los ejemplares adquiridos ${ }^{65}$ - también se ha constatado que algún libro de la colección de Quevedo no se localiza en el inventario de Med. 1673 y sin embargo ha sido descrito por los monjes benedictinos en los índices de libros de su biblioteca y alguno de ellos además conserva la signatura topográfica que lo emparenta con la colección de S. Martín:

\section{Cirilo, Santo, Obispo de Jerusalén (ca. 315-387) ${ }^{66}$}

S. Patris nostri Cyrilli Archiepiscopi Hierosolymorum Catecheses illuminatorum Hierosolymis XVIII et V mystagogicae: quae tempore nunc primum latinitate donatae in lucem prodeunt Ioanne Grodecio... interprete. Antuerpiae: excudebat sibi \& Materno Cholino, ciui Coloniensi, Christophorus Plantinus, 1564.

Localización: BNE, R. 38420.

Exlibris manuscrito de Francisco de Quevedo. En portada, tres letras hebreas $^{67}$. En la h. de guarda, nota autógrafa de Quevedo: «Costó 6 reales». Numerosísimas notas en los márgenes de mano de Quevedo. Una nota manuscrita indica que procede del monasterio madrileño: «S. Martín», además de figurar la signatura topográfica de su biblioteca: «Cajón 7».

relacionadas con la adquisición de libros que realiza en su nombre: «No me dieron la memoria de los duplicados con todo buscaré las Republiquillas y si las hay, las llevaré», «Pedro Mallarte que es quien tiene los libros que a vuecelencia faltan, no quiere los duplicados, por ser libros en romance» (Quevedo, op. cit., págs. 238, 272 y 276).

${ }^{64} \mathrm{~F}$. Moya del Baño, op. cit., pág. 484, reseña —en el listado de obras citadas indirectamente por Quevedo o mencionadas por él o de las que tuvo ejemplares - la titulada «Politicorum siue ciuilis doctrinae libri sex, qui ad Principatum maxime spectan. Additae notae auctiores, tum et De una religione liber. Antuerpiae, ex oficina Plantiniana, apud Ioannem Moretum, 1599». También señala que de esta obra había un ejemplar en S. Martín 1788.

${ }^{65}$ No debemos olvidar aquella nota del inventario de la biblioteca de Med. 1673 en la que se hace referencia a que los frailes de San Martín pagaron por la librería veinte y tantos mil reales de vellón y «ellos sacaron más dinero de los duplicados que vendieron» y quizá no solo se vendieron los duplicados (M. C. Álvarez Márquez, op. cit., pág. 10).

${ }^{66}$ I. Pérez Cuenca, «Localización y descripción de algunos impresos de la biblioteca de Quevedo», en I. Lerner, R. Nival y A. Alonso, Actas del XIV Congreso de la Asociación Internacional de Hispanistas. Literatura Española, siglos XVI y XVII, Juan de la Cuesta, Newark (Delaware), 2004, págs. 451 y 457, trabajo en el que se dio noticia de su hallazgo. Este ejemplar ha sido objeto de un detallado y riguroso estudio, véase V. Nider, «Las anotaciones quevedianas a las Catecheses de San Cirilo de Jerusalén", Perionala. Revista anual de investigación quevediana, 17, 2013, págs. 259-299.

${ }^{67}$ Esas tres letras hebreas figuran en otros ejemplares de la biblioteca de Quevedo, su sentido es, leyendo de derecha a izquierda, Tau Lámed Jet, acrónimo de Tehil.lá La-El Jai (Alabanza al Dios Vivo). 


\section{Repertorios:}

- S. Martín 1699, fol. 21v: Cyrilo Jerosolimitano 01 01; fol. 92r: Cajón 1 Cyrilli Hierosolymitani Cathechesis 01.

- S. Martín 1730, f 57v: Cirili Hierosolimitani catecheses 18.

- S. Martín 1788, fol. 131r: Cirili Jerosilimitani. Catecheses. Antuerpiae, 1564.

En el inventario de Med. 1673 [185] encontramos una obra de San Cirilo: «San Zirilo sus Obras, vn tomo de marca mayor, en çiento y çienquenta y quatro reales», pero estos datos no concuerdan con los del ejemplar firmado y anotado por Quevedo 68 , incluso podrían referirse a las obras de San Cirilo, patriarca de Alejandría, registradas en el inventario de San Martín:

\section{Repertorios:}

- S. Martín 1699, fol. 21v: Cyrilo Alexandrino 07 04; fol. 93v: Cajón 4 Cyrilli Alexandrini opera 07.

- S. Martín 1730, fol. 57v: Cirili Alexandrini 7 [9?].

- S. Martín 1788, fol. 131r: Cirilij Alexandrini Opera. Coloniae. 154669.

Al igual que sucede con el ejemplar de San Cirilo, patriarca de Alejandría, se halla en los tres catálogos de S. Martín 1699, 1730 y 1788 consultados un libro de Hesíodo que perteneció a Quevedo, con su firma en la portada que no logramos localizar en Med. 1673.

\section{Hesíodo}

Hesiodou Askraiou Ta Heuriskomena. Hesiodi Ascraei quae extant. Daniel Heinsius Interpretationem infinitis locis emendauit. Introductionem in Opera \& Dies, in qua Hesiodi philosophia nunc primum exponitur, item notas, addidit. Lugduni Batavorum: ex officina Ioannis Patij, iurati \& ordinarij Academiae typographi. [S.1.]: prostant in Bibliopolio Commeliniano, 1613.

Localización: Biblioteca de la Universidad de Salamanca, BG/3386170.

${ }^{68}$ La dimensión de un libro de marca mayor es superior a la de folio, por tanto, hemos de suponer que el ejemplar descrito no es el mismo que se halla en la BNE (R. 38420), puesto que se imprimió en 8 .

${ }^{69}$ Esta edición podría ser la siguiente: Divi Cyrilli archiepiscopi Alexandrini Operum omnium... Coloniae: Melchior Novesianus, 1546.

${ }^{70}$ No hemos visto este impreso, por lo que desconocemos si este ejemplar tiene una signatura antigua del monasterio en alguna de sus hojas. Toda la información sobre él se ha obtenido del catálogo de la Biblioteca de la Universidad de Salamanca. Catálogo [en línea]. Salamanca: Universidad de Salamanca. <http://brumario.usal.es/> [consulta: 26 de febrero de 2015]. Dio noticia de la existencia de este ejemplar y de otros que se citarán más adelante, todos ellos propiedad de Quevedo, I. Pérez Cuenca, «Entre Quevedo y Medinaceli: La biblioteca de un humanista del Siglo de Oro», conferencia dictada el día 15 de septiembre de 2010 en el Congreso The Republic of Letters and the Empire of the Two Worlds: Culture and Society in Baroque Spain, organizado por The University of Nottingham, The Graduate Center (CUNY), The Hispanic Society of America y el Instituto Cervantes (Nueva York), celebrado los días 14-16 de septiembre de 2010 en la ciudad de Nueva York (inédita). 
En portada leemos varios exlibris manuscritos: De la librería del colegio mayor de Cuenca. [Tachado:] Francisco de Quevedo. De don García de Salcedo Coronel; otro exlibris guillotinado. En verso de portada nota manuscrita erudita de letra de Quevedo, con una extensión de 20 líneas, firmada: «Don Francisco de Quevedo Villegas» [tachado].

Contiene las versiones en griego y latín de los Opera et dies, Scutum Herculis; Deorum generatio; más el texto griego de los Fragmenta, seguidos al final de la Introductio y Notae de Heinsius a los Opera et dies.

\section{Repertorios:}

- Quev. 1646 [151/136]: «Hesiodi ascrie, Opera, fo, en tres reales» ${ }^{71}$.

- S. Martín 1699, fol. 42r: Hesíodo 02 82; fol. 119r: Cajón 82 Hesíodo 02.

- S. Martín 1730, fol. 102v: Hesiodi Poemata grec-lat 1197.

- S. Martín 1788, fol. 206v: Hesiodi Afeci. Opera cum Danieli Hinsio. Lugduni Batav. 1613.

Como vemos hay lagunas en unos y otros repertorios que alejan de la total correspondencia entre ellos. En ocasiones esto se debe a la imposibilidad de identificar la obra reseñada por la ambigüedad de la información o carencia de ella, los ejemplos previos pueden apuntar en esta dirección, pero no descartemos la opción de que no todas las obras compradas no estaban descritas en Med. 1673 de igual manera que no todo lo reseñado allí fue adquirido por el monasterio - el libro de Bonatti lo demuestra- . Volviendo a Lipsio, comprobamos que hay varias obras de este autor en repertorios de la casa ducal posteriores a Med. 1673, por ejemplo, en el índice de libros griegos y latinos, Med. 1759, se describen dos del humanista flamenco: a) Iusti Lipsi Animaduersiones in tragoedias quae L. Annaeo Senecae tribuuntur. Lugduni Batavorum: [ex officina Plantiniana: apud Franciscum Raphelengium], 1588, encuadernado en pasta y b) Epistolarvm selectarvm, centuria prima Iustus Lipsius. Antuerpiae: [apud Christophorum Plantinum], 1586, con una encuadernación en pergamino. Quizá podrían encontrarse aquí descritos otros ejemplares de la «biblioteca imaginaria» ${ }^{72}$ de Quevedo.

Es inevitable sospechar, a la luz de los resultados obtenidos a la hora de cotejar todos estos inventarios de libros e índices de bibliotecas, que no se registró en el inventario de 1673 toda la colección del vil duque de Medinaceli, se ha de tener muy presente que en este documento solo se describe para su tasación, tal y como en él se indica, los libros que poseía el duque en su palacio del Puerto de Santa María, y que regresaron a Madrid en 1731[?], junto

${ }^{71}$ Mantenemos la abreviatura fo. al igual que hizo Maldonado; Fernández y Simões optaron por desarrollarla por «firmado». Consideramos que la posibilidad de que indique en ocasiones el tamaño del libro no es descabellada, con total seguridad hace referencia a las dimensiones «de a folio» en los ítems [89/79] y [117/105].

${ }^{72}$ Utilizo la expresión de biblioteca imaginaria en el mismo sentido que ya la empleó S. López Poza, «La cultura de Quevedo: Cala y cata», en S. Fernández Mosquera (coord.), Estudios sobre Quevedo. Quevedo desde Santiago entre dos aniversarios, Universidad de Santiago de Compostela, 1995, 69-104, pág. 90: «biblioteca imaginaria de Quevedo, es decir, los libros que poseyó, consultó, citó, leyó». 
con los del palacio sevillano, con el objetivo de reunir en un solo lugar toda la colección de la casa ducal de Medinaceli.

También parece poco probable que se vendiese al monasterio el fondo completo reunido en el inventario de 1673 después del año 1730, pues de acuerdo con la propuesta de Maldonado, no son pocos los libros de Quevedo, cuya descripción bibliográfica coincide primero con los datos de Med. 1673 y estos con los de S. Martín 1699 y 1730.

Por otro lado, no es excepcional que localicemos en los repertorios de Med. 1673 y en alguno o en todos los de San Martín un libro firmado por Quevedo y este no sea identificado en Quev. 1646:

\section{DE VITo, Giovanni}

Ioannis De Vito... De causis nostrarum calamitatum et de morbis epidem: qui vulgabantur per totum regnum Neap. anno d[omi]ni 1600. Cum pronosticis vsq[ue] ad annum 1608. Neapoli: apud Io. Iacobum Carlinum typographum Curiae Archiepiscopalis, $1602^{73}$.

Localización: Biblioteca Histórica «Marqués de Valdecilla» (Universidad Complutense de Madrid), BH MED $3702^{74}$.

En h. de guarda se lee una signatura topográfica del monasterio de San Martín: «C. 187».

\section{Repertorios:}

— Med. 1673 [1126]: Ytten Juan de Viso De la causa de la calamidad, tomo en quarto, seis reales.

- S. Martín 1699, fol. 55r: Joan de Vito 01 194; fol. 170v: Cajón 194 Joann. Vitus de morbis 01.

- S. Martín 1730, fol. 207v: Vito (Joannis) de Causis nostrarum infirmitatum opus 1.

-S. Martín 1788, fol. 407r: Vito (Joannis). De causa nostrarum Calamitatum, et de Epidem. Neapoli anni 1600. Neapoli. 1602.

No debemos descartar la incapacidad de identificar los libros descritos en unos inventarios e índices por las escuetas descripciones, lo que impide seguir el rastro del libro de un repertorio a otro. Este puede ser el caso de la Historia varia de Eliano, libro firmado, anotado y subrayado por Quevedo:

\section{Eliano, Claudio}

Aeliani De varia historia libri XIII: nunc primum \& latinate donati \& in lucem editi Iusto Vulteio vveterano interprete; item, De politis siue rerum

73 I. Pérez Cuenca, «Entre Quevedo y Medinaceli», dio noticia de este libro.

74 Descripción tomada de Universidad Complutense de Madrid, Biblioteca Histórica «Marqués de Valdecilla». Catálogo Cisne [en línea], Universidad Complutense de Madrid: $<$ http://biblioteca.ucm.es/historica $>$ [consula: 26 de febrero de 2015]. Junto a la referencia bibliográfica, puede consultarse una reproducción digital del impreso completo. 
publicarum descriptiones ex Heraclide, eodem interprete. Basileae: ex oficina Ioannis Oporini..., 1548.

Localización: BNE, R. $9560^{75}$.

- Med. 1673 [1423]: Eliano de varias historias, tomo en octabo, en seis reales.

- S. Martín 1699, fol. 27r: Eliano 02 125; fol. 140v: Cajón 125 Aeliani. Opera 02.

- S. Martín 1730, fol. 2v: Aeliani de varia historia Baselea an 1548 [...] 1147.

- S. Martín 1788, fol. 4r: Aeliani Historiae variae Romae 1545 [en línea inferior] Yt Basilea 1548.

Ningún ítem bajo el nombre de Eliano tenemos en el inventario de bienes de Quevedo, pero sí hay uno que bien pudiera describir sin precisión el volumen que hoy conserva la BNE:

-Quev. 1646 [189/160]: Historias.

Además sabemos de libros con el exlibris autógrafo de Quevedo que no figuran en ninguno de los repertorios empleados en el proceso de reconstrucción de su biblioteca hipotética, hecho que confirma, en primer lugar, lo que ya advirtió Maldonado en el año 1975: en Quev. 1646 no están todos los libros que formaron parte de su biblioteca personal, y, en segundo lugar, Medinaceli no sumó a su biblioteca la colección completa de libros propiedad de Quevedo:

\section{DRIEDO, Johannes (1480-1535)}

Ioannis Driedonis... De concordia liberi arbitrij, \& praedestinationis diuinae, liber unus. Louanii: ex officina Rutgeri Reseij, $1537^{76}$.

Localización: Biblioteca Histórica «Marqués de Valdecilla» (Universidad Complutense de Madrid), BH FLL $6890^{77}$.

Quevedo anota en $\mathrm{h}$. de guarda «Costó 4» y en portada «Costó 6 reales». En la portada, bajo la firma y rúbrica de Quevedo (d. francisco-de Quevedo-Villegas) se lee: «Es de la casa Profesa de la Compañía de Jesús de Madrid».

No localizamos referencia alguna a esta obra en los repertorios consultados. En los tres índices de San Martín se describen otras obras de este autor que podrían ser las mismas que reseña el inventario de Med. $1673^{78}$.

${ }^{75}$ Ha sido estudiado por L. Schwartz e I. Pérez Cuenca, op. cit.

${ }^{76}$ I. Pérez Cuenca, «Entre Quevedo y Medinaceli», dio noticia de este libro y de los tres que siguen.

77 Referencia bibliográfica tomada de Universidad Complutense de Madrid, Biblioteca Histórica Marqués de Valdecilla, incluye reproducción digital del ejemplar [consulta: 28 de febrero de 2015].

78 a) S. Martín 1699, fol. 50r: Joan Driedono 02 62; fol. 112r: Cajón 62 Joann. Driedonij opa 02; b) S. Martín 1730, fol. 71v: Driedonis (joannis) de ecclesiasticis scripturis et dogmatib' lib 4/de cativitate et redemptione humani generis lib. 12 360; c) S. Martín 1788, fol. 159v: Driedoni (Joannis) De captiuitate et redemptione humani generis. Lovani. 1548./Ejusd: De ecclesiasticis scripturis et dogmatibus. Lovani. 1543; d) Med. 1673 [301]: Ytten Driedo De los domas eclesiásticos, vn tomo en folio, diez y seis reales; Med. 1673 [302]: Ytten Driedo De captibitate, vn tomo 


\section{LASCARIS, Constantino}

In hoc libro haec habentur Constantini Lascaris Byzantini De octo partibus or[ati]onis liber I.; eiusdem De constructione liber secundus; eiusdem De nomine \& uerbo liber tertius; eiusdem De pronomine in omni idiomate loquendi, ac ut poetae utuntur opusculum; Haec omnia habent e regione latinam interpretationem ad uerbum fere propter rudiusculos, ita tamen ut \& amoueri, \& addi possit pro cuiusq[ue] arbitrio; Cebetis tabula \& graeca \& latina, opus morale, \& utile omnibus, \& praecipue adulescentibus; De literis graecis ac diphthongis $\&$ que [m]admodu[m] ad nos uenia[n]t; Abbreuiationes, quibus frequentissime graeci utuntur; Oratio dominica \& duplex salutatio ad beatiss.Virginem; Symbolum Apostolorum; Euangelium diui Ioannis Euangelistae; Carmina aurea Pythagorae; Phocylidis poema ad bene, beatéq[ue] uiuendum; De idiomatib[us] linguarum tres tractatus Ioannis grammatici; Eustathii Corinthi cum interpretatione latina; Introductio perbreuis ad hebraicam linguam. Venetiis: apud Aldum, mense octobri 1512.

Localización: Biblioteca Histórica «Marqués de Valdecilla» (Universidad Complutense de Madrid), BH FLL Res. $306^{79}$.

Exlibris autógrafo de Quevedo en portada: «es de Don francisco Gómez de Quevedo».

\section{Terencio Africano, Publio}

Terentius, in quem triplex edita est P. Antesignani Rapistagnensis Commentatio. Primum exemplar commentariolum est ex omni interpretationu $[\mathrm{m}]$ genere..., secundum exemplar praeter singula contenta in primo, omnium fere quotquot sunt qui in Terentium aliquid ediderunt, commentarios, expositiones, annotationesque complectitur, tertium exemplar ex omnium interpretum commentariis compe[n] diosam expositionem, omnéque primi exemplaris argume[n]tum, Gallicam praetereà translationem ad verbum in tres priores comoedias... continet: horum omnium ratio in praefatione reddita est. Lugduni: apud Mathiam Bonhome, sub Claua Aurea, 1560.

Localización: Biblioteca de la Universidad de Salamanca, BG/3367480.

en folio, diez y seis reales. Tal vez correspondan a esas descripciones las ediciones siguientes: 1) Ioannis Driedonis... De captiuitate \& redemptione humani generis liber unus; nunc denuo ab innumeris... mendis absterus; adiectis in marginibus tum sententiarum quae tractantur... locis. Louanii: ex officina Bartholomei Granii, 1548; en folio, y 2) Ioannis Driedonis a Turnhout... de ecclesiasticis scripturis \& dogmatibus libri quatuor à mendis non paucis per Theologos Academiae Louaniensis uindicat... Vaenundantur Louani: a Bartholomaeo Grauio, sub Sole aureo, 1543; en el colofón: Coloniae: excudebat Iaspar Gennepaeus; en folio.

${ }^{79}$ La descripción biliográfica se toma de Universidad Complutense de Madrid, Biblioteca Histórica «Marqués de Valdecilla», aquí también puede consultarse una reproducción digital del impreso [consulta: 28 de febrero de 2015].

${ }^{80}$ No hemos visto el ejemplar, la descripción de este libro se toma del catálogo de la Biblioteca de la Universidad de Salamanca, op. cit. 
Anotaciones manuscritas en portada: «Don Francisco de Quevedo Villegas»; exlibris D. Octauij Brancifortij md.

También nos hemos encontrado con el caso contrario, es decir, tener un impreso que perteneció a Quevedo sin información sobre autoría, título y pie de imprenta. Con los datos que ofrecen los repertorios no se ha podido reconocer en ninguo de los repertorios una entrada que concuerde con los datos del impreso:

[BALBOA DE MOGROVEJo, Juan de] ${ }^{81}$

Señor. La uniuersidad de Salamanca y la de Alcalá acuden a los pies de V. Magestad suplicándole... se sirua de fauorecerlas, en la pretensión que los Padres de la Compañia han mouido agora, de fundar en esta Corte una Universidad ò Estudios Generales... [s. 1.: s. n., s. a.]

Localización: Real Acacemia de la Historia, 9/1032(11), fols. 179r-202r.

Como se ha demostrado, los inventarios y catálogos mencionados son de gran ayuda, aunque insuficientes, para acometer la reconstrucción global de la biblioteca hipotética del polígrafo áureo, por ello se hace obligatorio recurrir a otro tipo de recursos. Ha quedado probado que son fundamentales en este sentido las citas y reminiscencias de las obras de otros autores en sus propios textos, los trabajos de S. López Poza y de Francisca Moya del Baño son la mejor prueba de ello ${ }^{82}$. No son de menor utilidad las noticias que el propio Quevedo ofrece en sus obras y documentos que le pertenecieron. Este es el caso del manuscrito facticio 9/1032 de la Biblioteca de la Real Academia de la Historia que colecciona papeles que pertenecieron a Quevedo ${ }^{83}$. Entre otros muchos impresos, encontramos

${ }^{81}$ Carece de autor, título y pie de imprenta. La adjudicación de esta obra a Balboa de Mogrovejo tiene su origen en una nota autógrafa, al final del impreso, de Aureliano Fernández Guerra: «Presentóse el año de 1627 a S. M. El autor de este Memorial fue el doctor Juan de Balboa Mogrovejo, catedrático de prima de cánones en Salamanca. Las apostillas marginales, de puño e intención de don Fran ${ }^{\mathrm{co}}$ de Quevedo y Villegas [firma y rúbrica de Fernández Guerra]»; sigue una nota de Gayangos: «Examinado por mí». La descripción se toma de Real Academia de la Historia, Biblioteca [en línea]: Catálogo general, [Madrid]: RAH <http://www.rah.es/biblioteca.htm> [consulta: 26 de febrero de 2015]. De este impreso dio noticia I. Pérez Cuenca, «Entre Quevedo y Medinaceli». Esta misma biblioteca posee otro ejemplar de este memorial, con una nota manuscrita que lo data el 30 de marzo de 1627 [signatura: 9/3715 (8)].

82 S. López Poza, Francisco de Quevedo y la literatura patrística, Universidade da Coruña, 1992, y F. Moya del Baño, op. cit. En el primero se ofrece el repertorio de los textos patrísticos presentes en la obra de Quevedo junto con un amplio abanico de sus ediciones. En el segundo, a la localización de la cita clásica en los escritos quevedianos se suman las ediciones empleadas por el escritor áureo y en ocasiones se aporta el ejemplar propiedad de Quevedo o del monasterio de San Martín, señalando cuando es pertinente si la obra figura en Quev. 1646 o en el índice de S. Martín 1788.

${ }^{83}$ Es un ms. de la Colección de Luis Salazar y Castro (N. 27) del que realizamos un detallado estudio. «Un volumen en folio, de manuscritos e impresos, encuadernados en pergamino, con pastas sueltas y 324 hojas numeradas, más una en blanco, dos de índices y otras dos más 
un ejemplar de su Carta a Luis XIII con anotaciones autógrafas ${ }^{84}$, entre ellas una que leemos en la h. de guarda que antecede a la portada ${ }^{85}$ :

[1ํ] escribió en latín Mario Equicola, jentilombre italiano, vna apología contra los maldicientes de la Nación Francesa. Tradúxole en Francés Michel Rote, imprimióse em París por Vicencio Sertenas Año 1550. Refuta Ridículamente los lugares de Julio César. C. Tácito. Tito Liuio, i Lucio Floro. escribió Equicola de Amor, i fue hombre erudito. [2.] Escribió en latín Victor Tuartio Pro Franco Galli Contra mendatia, imposturas, et Calumnias Joannis Meinardi Frisij, in Academia Pictaviensi leguleis. Parisiis apud Bartholomeum Maceum Anno 1611. Ni el vno, ni el otro necesita de respuesta, puesto dos sus libros son vn esfuerzo infeliz del injenio, o mandado, o vendido desearon defender a Françia, i no pueden defender su defensa.

[3.] AELIVS LAMPREDIUS. in vita Alexandri Severi. Verum Gallicane mentes, vt sese habent dure, ac retrograde, et sepe Imperatoribus graues, severitatem hominis nimiam, et longe maiorem post Heliogabalum, non tulevunt.

1.) EQUiCola, Mario (1470-1525)

Apologie de Marius Equicolus, gentilhomme italian, contra les mesdisantz de la nation françoise traduicte de latin en François [par Michel Roté]. París: V. Sertenas, 1550. Dimensiones: $8^{0.86}$

\section{2.) Tuartius, Victor}

Apologia victoris Tvuartii pro Francogallis contra mendacia, imposturas \& calumnias Joannis Meinardi... Parisiis: Apud Bartholomevum Macoevm, 161187. Dimensiones: $8^{\circ}$.

escritas, todas sin numerar al principio, y otra al final en blanco, también sin numerar. "En el lomo se lee: N-27./Misce/láneas./T. XXVII./Ms./Quevedo". Es el tomo XXVII de las Misceláneas en folio del marqués de Montealegre», véase B. Cuartero y Huerta y A. de Vargas-Zúñiga y Montero de Espinosa, marqués de Siete Iglesias, Índice de la colección de don Luis Salazar y Castro. Escrituras, extractos de ellas, genealogías y noticias de personajes y familias. $\mathrm{N}-1$ al N-33 (números 59.800 al 61.699), Real Academia de la Historia, Madrid, 1967, XXXVIII, págs. 319-333, 319; acceso on-line: <http://www.rah.es/pdf/SalazaryCastro.pdf >.

${ }^{84}$ Véase el ilustrador estudio de C. Peraita Huerta, «Mapas de lectura, diálogos con los muertos: La Carta a Luis XIII y las anotaciones en el ejemplar de la Utopía de Quevedo», Perinola. Revista de estudios quevedianos, VIII, 2004, págs. 322-341.

${ }^{85}$ Hoja sin numerar entre los folios 114 y 115 . Véanse las observaciones a esta nota y una reproducción de ella en C. Peraita Huerta, loc. cit., págs. 330-333 y 341.

${ }^{86}$ Referencia bibiográfica correspondiente al ejemplar descrito en el catálogo de la Bibliotèque Nationale de France. Catalogue général [en línea]. [París]: Bibliotèque Nationale de France. $<$ http://catalogue.bnf.fr/ark:/12148/cb30402231c>, login: 'BnF' [consulta: 28 de febrero de 2015].

${ }^{87}$ La referencia bibliográfica corresponde al ejemplar descrito en Biblioteca Nacional (España). Ariadna [en línea]: catálogo automatizado de la Biblioteca Nacional. [Madrid]: Biblioteca Nacional. <http://catalogo.bne.es/uhtbin/webcat>, login: 'bn' [consulta: 28 de febrero de 2015]. 


\section{Repertorios:}

- Med. 1673 [1140]: Apología de Francisco Gallo, vn tomo en quarto, en quatro reales.

- S. Martín 1699, fol. 89r: Victor Tuarto 01 46; fol. 166v: Victor Thuartus de franco-Gally 01.

- S. Martín 1730, fol. 200r: Tuarcy [sic] (Victoris) pro Franco Gallys pro imposturis et calumniis Juannis Mainardy Frisi in Academ Pictv 1154.

- S. Martín 1788, fol. 393r: Tuartii, Victoris, Apologia Victoris Tvartii pro Francogallis, contra mendacia, imposturas et calumnias Ioannis. Meinardi Frisii, Parisis, 1611.

\section{3.) Historiae Augustae...}

Historiae Augustae Scriptores VI. Aelis Spartianus, Julius capitolinus, Aelius Lampridius, Vulcatius Gallicanus, Trebellius Pollio, Flanius Vopiscus. Clavdivs Salmasin, ex veteribvs libris recensivit. et librum adiecit notarvm ac emendationvm. Qvib. adyunctae sunt notae ac emendationes Isaaci Cazavboni iam antea editae. Parisiis: [Hierosme Drovart, Marchand Libraire \& censons], MDCXX ${ }^{88}$. Dimensiones: folio

- Quev. 1646 [13/6]: Ysaçi Causaboni, fo, en tres reales ${ }^{89}$.

- S. Martín 1699, fol. 20r: Claudio Salmasio 01 69; fol. 114v: Claudius Salmasius de scriptoribus auguste historie 01.

- S. Martín 1730, fol. 179v: Salmasy Claudii Notae in Aelium Spartianum et alios Hist. Augustae 1137.

- S. Martín 1788, fol. 349v: Ejusd /Salmasii [sic] (Claudi)/, et Casauboni Isacii: Notae in Scriptores Historiae Augustae. Parisis. 1620.

La nota de Quevedo sobre esta última obra ofrece un número de detalles insuficiente para identificar la edición, al contrario de lo que sucede en las dos anteriores, sin embargo ha sido posible ofrecer los datos bibliográficos de la edición que pudo pertenecer a Quevedo gracias a los índices de S. Martín ${ }^{90}$.

Tampoco son despreciables algunas noticias que saltan sobre la biblioteca de Quevedo al hilo de otras investigaciones, como sucede con la valiosa información que Trevor Dadson ${ }^{91}$ ofreció a los quevedistas cuando desempolvó

${ }^{88}$ Referencia bibliográfica tomada del ejemplar que se describe en Biblioteca Nacional (España), loc. cit.

${ }^{89}$ Maldonado ya apuntó la posibilidad de que se tratase de uno de los comentarios de Casaubon (op. cit., pág. 421). Solo lo podremos confirmar con total certeza si hallamos el ejemplar de Quevedo.

${ }^{90}$ F. Moya del Baño, op. cit., pág. 429, apunta hacia la edición de 1603, señala en nota que «el texto que cita Quevedo coincide con el de esta edición, salvo en una lectura: tholo (que no ha encontrado en ninguna edición), en vez de solo».

${ }_{91}$ T. Dadson, «Las bibliotecas de la nobleza: dos inventarios y un librero, año de $1625 »$, en A. Egido y J. E. Laplana (eds.), Mecenazgo y humanidades en tiempos de Lastanosa. Homenaje a Domingo Ynduráin, Instituto de Estudios Alto Aragoneses/Institución Fernando el Católico, Huesca/Zaragoza, 2008, págs. 252-302, 266, 280 y 294. 
el documento de la almoneda de libros de Francisco de Mendoza, obispo de Sigüenza y almirante de Aragón, en el que consta que Francisco de Quevedo, caballero del hábito de Santiago, adquirió el 15 de mayo de 1625, en la segunda almoneda, el lote 8 por 50 reales $^{92}$. Ese lote lo forman los siguientes libros:

1) «Un tratadillo de mano de natura rerum en verso», según Dadson se trata de una versión manuscrita de la conocida obra de Tito Lucrecio, De rerum natura.

No detecto ningún manuscrito que responda a estos datos en Med. 1673, tan solo la partida $[1142]^{93}$ podría relacionarse con ese tratadillo, pero no se dice que sea de mano o manuscrito, como sucede en otros ítems. Sin embargo, en los índices de S. Martín hallamos un asiento que encaja perfectamente con la identificación de Dadson.

\section{Repertorios:}

- S. Martín 1699, fol. 60v: Lucrecio $01128^{94}$.

- S. Martín 1730, fol. 119r: Lucrecij cari de rerum nat. 85 n. 4.

-S. Martín 1788, fol. 241v: Lucrecij Cari: De Rerum Natura. Francofurti, 1583 [estante] 85 [n.] 495 .

En S. Martín 1730 se ha insertado esta entrada en un momento posterior que el conjunto mayoritario de sus referencias bibliográficas, no se señala el número de cajón, pero sobre la línea de escritura se lee: «[estante] 85, n. 4», nuevo sistema de organización en la biblioteca que sucede al de cajón. Es muy importante tener en cuenta que en el repertorio de S. Martín 1788 no se registra ningún manuscrito de Tito Lucrecio Caro, pues la referencia bibliográfica transcrita en líneas anteriores corresponde sin duda a un impreso ${ }^{96}$. Sin duda, este libro es el mismo que el descrito en S. Martín 1730, a tenor de la coincidencia que se produce con la signatura topográfica que en ambos

${ }_{92}$ Véase también F. Bouza Corre manuscrito. Una historia cultural del Siglo de Oro, Marcial Pons, Madrid, 2001, págs. 39-40.

93 «Ytten Bernardino de Telezía De Naturaleza de las cossas, vn tomo en quarto, en catorze reales».

${ }^{94}$ En este cajón no hay ningún asiento para Tito Lucrecio Caro. El cajón 128 se reservó a los manuscritos, junto con el 127 y el 129, posteriormente se tachó la palabra manuscritos que figuraba bajo el número de cajón y dos entradas: «Thome Yanez Choronica de don Ju․ de Portugal 03/Diez y seis tomos en arábigo 16» (S. Martín 1699, fol. 142v). La signatura C. 128 se llenó con otras obras que fueron insertadas en este índice por una mano diferente. No nos ocupamos aquí de los manuscritos, esta parte la dejamos para mejor ocasión.

${ }_{95}$ Excepcionalmente se transcribe la signatura topográfica asignada a este libro por la transcendencia que tiene para la identificación del ejemplar adquirido por Quevedo en la almoneda.

${ }^{96}$ Creemos que el impreso puede ser: T. Lucretii Cari de Rerum natura libri VI a Dion. Lambino... emendati... et... commentariis illustrati; nunc ab eodem recogniti... Francofurti: apud haeredes Andreae Wecheli, 1583. Un ejemplar de esta edición pudo poseer Quevedo, recordemos que Maldonado se hace eco de la venta anunciada «en un catálogo de la librería de nuestro buen amigo Don Antonio de Guzmán» de un Rerum natura de Lucrecio (op. cit., pág. 406 , nota 8 ). 
índices se otorga a esa obra (estante $85, n^{\circ}$. 4). Pero existe otro índice de la biblioteca del monasterio al que nos interesa recurrir ahora, este registra solo manuscritos de la colección benedictina:

- S. Martín 1770, fol. 299v97: Lucrecio Caro: De Natura Rerum: escrito en pergamino fino y a lo último de él dice: Ambrosius scripsit. Este 3ํ. n. 18.

La escueta descripción que se realiza del manuscrito de la biblioteca del monasterio de Madrid permitió a Gregorio de Andrés localizarle en la BNE ${ }^{98}$. Las características del manuscrito por él propuesto, ms. 2885, concuerdan perfectamente con los apuntes del índice, pudiendo ser ese el que poseyó el monasterio benedictino. Por un lado, el manuscrito perteneciente de la BNE recibe una encuadernación en pasta del siglo XIX, así pues la de época y sus correspondientes guardas originales se han perdido y con ellas la antigua signatura topográfica. Pero por otro, comprobamos que el material de escritura es la vitela, es decir, «un pergamino fino» y que, como en el que describen los benedictinos, al final se lee: «Ambrosius scripsit», de forma que ambos aspectos emparentan el ms. 2885 con el que se cataloga en el índice de S. Martín 1770. Sin embargo, aunque se encuentre en la biblioteca del monasterio ya en 1699, al igual que otros muchos libros pertenecientes al escritor, no se puede afirmar con absoluta seguridad que este manuscrito sea el mismo que adquirió Quevedo en la almoneda, pues en él no vemos ninguna huella del escritor madrileño ${ }^{99}$.

2) «Un librillo de mano en verso». Con estos datos no es posible identificar el contenido y mucho menos localizar el manuscrito ${ }^{100}$.

3) «Ordenaciones del rey don Fernando escrito de mano», Dadson cree que puede ser una versión manuscrita de Ordenanzas reales de Castilla, Sevilla, 1492 de Alfonso Díaz de Montalvo.

${ }_{97}$ Citamos ahora el «Ýndize de todas los manu-scriptos que se hallan oy 23 de agosto de 1770 en este archivo de $\mathrm{S}^{\mathrm{n}}$ Martín de Madrid en la alazena del medio, se pone su estante y número en cada tomo», se copia a continuación del Índice y Inventario de todas las esripturas del Archivo de esta Real Casa y Parroquía de San Martín de Madrid, BNE, ms. 1916 (fols. 297r-300r).

98 G. de Andrés, op. cit., pág. 260, no 76.

${ }^{99}$ BNE, ms. 2885: Titus Lucretius Carus. De natura rerum. Copiado en vitela en el siglo XV, con iniciales miniadas de estilo florentino, los títulos en rojo, en el fol. 1 se conserva una pintura heráldica que consiste en un círuculo dorado, con una faja azul con tres estrellas doradas de seis puntas (en uno de los ejemplares del tomo ix del Inventario General de manuscritos de la Biblioteca Nacional, que puede consultarse en la Sala Cervantes de esa biblioteca, se anota a mano que la pintura heráldica es el «Escudo de Martinozzi de Siena»); formado por 163 fols +3 h. de guarda $(0+3), 270$ x $205 \mathrm{~mm}, 25$ líneas, caja: 185 x $105 \mathrm{~mm}$. Enc. en pasta, s. XIX, 280 x $210 \mathrm{~mm}$. Tejuelo: Lucretiu de Natura Rerum. Descripción tomada de Biblioteca Nacional, Inventario general de manuscritos de la Bibioteca Nacional, Dirección General de Archivos y Bibliotecas, Madrid, 1970, t. IX.

100 Ya dijimos al comienzo que no son pocas las entradas en los repertorios que ofrecen escasa información o muy genérica de los libros descritos, lo que hace imposible avanzar en la labor de reconstrucción de la biblioteca de Quevedo, este es un ejemplo de ello, al igual que los ítems de Quev. 1646 [77/70]: «Dos libros de manos, fo, en quatro reales», Med. 1673 [618]: «vn quadernillo de rimas manuescripta, en dos reales». 
4) «Un libro de sentencias de Portugal». Para esta descripción propone Dadson una de las muchas ediciones de la obra de Gabriel Pereira de Castro, Decisiones supremi eminentissimique senatus Portugaliae, Lisboa, Pedro Craesbeeck, 1621, donde «sentencias» equivale a «decisiones».

5) «Un manual libro ms del Orden de San Juan», sobre el que no podemos aportar dato alguno.

6) «Un libro de Martín del Río de las mágicas», Dadson apunta hacia la obra del Padre Martín del Río. Disquisitionum Magicarum, Lovanij, 1599. El índice de S. Martín 1788, fol. 337v registra ocho libros de Martín del Río, siendo el séptimo título «Disquisitiones Magicae. Moguntiae. 1624» ${ }^{101}$. También S. Martín 1699 y $1730^{102}$ tienen un asiento para este autor, pero no se identifica ninguna entrada en el inventario de Med. 1673 con la obra de Martín del Río ${ }^{103}$.

7) «Un mapa viejo».

8) «Nomenclator octilinguis». Ahora Dadson identifica la obra adquirida por Quevedo con la de «Adrianus Junius, Nomenclator octolinguis, Amberes, C. Plantino, 1583». En el inventario de Quev. 1646 no se halla un ítem que se ajuste a la obra de Junius, pero esta no es razón, como se ha comprobado, para descartar que el ejemplar adquirido por Quevedo en el año 1625 se integrase en la colección de Medinaceli tras su muerte:

—Med. 1673 [1159]: Nomendator [sic] con la explicazión de varias lenguas, vn tomo en quarto, en diez reales

- S. Martín 1699, fol. 3r: Adriano Junio 01 70, [otra mano anota en el margen izquierdo:] «No lo hallo» [y en el margen derecho, la misma mano, añade:] «duplicado», [en la línea siguiente se lee:] «Idem» [y, al lado, otra mano escribe:] «Expurgado», [a continuación] «01 137»; fol. 114v: Cajón 70 Adriani Junij nomen-clator omnium rerum 01; fol. 146v: Cajón 137 Adriani Junij nomenclator octo linguary 01 .

- S. Martín 1730, fol. 109r: Junij (Adriani) Nomenclator octo linguarum 1191.

${ }^{101}$ La edición que poseyó el monasterio probablemente fue Disqvisitionvm magicarvm libri sex qvibvs continetvr accvrata cvriosarvm artivm, et vanarvm svperstitionum confutatio, utilis theologis, iurisconsultis, medicis, philologis avctore Martino Del Rio Societatis Iesv Presbyter, ... Mogvntiae: Sumptibus Petri Henningii Bibliop. Colon., 1624.

${ }_{102}$ S. Martín 1699, fol. 66v: Martín del Río 08 42; fol. 105v: Cajón 42 Martini del Río Opera 09. S. Martín 1730, fol. 68v: Del-río (Martini) [...] Eiusdem Disquisit magicar [...] 4 36; este índice en total registra 9 tomos.

${ }^{103}$ Es de interés revisar el Catálogo de algunos libros curiosos y selectos para la librería de algún particular que desee comprar de tres a quatro mil tomos, de Martín Sarmiento, en A. Valladares de Sotomayor, Semanario erudito que comprehende varias obras ineditas... de nuestros mejores autores, antiguos y modernos. Tomo Quarto Madrid: por don Blas Román, 1787, 97-174, pág. 174, donde evalúa un corpus importante de obras, entre las que están las del padre Martín del Río, propiedad de la librería del monasterio e invita a los lectores a consultarlas: «Si alguno quisiere interesarse de todas las circunstancias, ediciones, vidas de los autores señalados, etc. o de los libros señalados en este catálogo o gustan ver por sí todos los libros casi con mucho gusto se le enseñarán en este monasterio de San Martín de Madrid desde hoy 14 de abril de 1748». 
- S. Martín 1788, fol. 220v: Julij (Adriani) Nomenclator octo-linguis. Genovae, 1619.

Podría tratarse de la edición Nomenclator octilinguis omnium rerum propia nomina continens ab Adriano Iunio... accesit huic postrema editioni alter nomenclator e duobus veteribus glossariis Hermanni Germbergii... Genevae: typis Iacobi Stoer, 1619, si consideramos los datos de impresión que aporta S. Martín 1788. Pero hay un problema para aceptar que esta edición proceda de la librería del duque, ya que la impresión genovesa se realizó en octavo y no en cuarto, como señala el inventario de Med. $1673^{104}$.

Finalmente, damos a conocer un nutrido conjunto de ejemplares pertenecientes a la biblioteca particular de Quevedo, la mayoría firmados en la portada por él y algunos además con anotaciones, subrayados u otras marcas:

\section{Du VAIR, Guillaume}

De l'Eloquence françoise et des raisons pour quoy elle est demeurée si basse. Paris: L'Angelier, 1606.

Localización: Libraire Jean-Claude Vrain ${ }^{105}$.

Encuadernado con: Traictez philosphiques. Par le Sr. D[u]. V[air]. Pr[ésident]. Au Parl[ement]. De Fr[ance]. Paris, Albel L'Angelier, 1606.

No se ha identificado con ninguna de las entradas de los reportorios consultados.

VIVALDI, Giovanni Ludovio (O. P.) ${ }^{106}$

Opus regale $i[n]$ quo continentur infrascripta opuscula: epistola Consolatoria... Prea[m]bulum Sequentis opusculi in quo agit[ur] de officio pietatis in defunctos... Tractatus Aureus de pugna partis sensitiue et intellectiue... Epistola Tota notabilis in qua multa curiosa sub breuibus tanguntur... Tractatus Totus curiosus de laudibus ac triumphis trium liliorum... Tractatus Optimis [et] cu[n]ctis necessarius de cosnitione elector[um] a reprobis. Tractatus De duodecim p [er] secutionib[us] eccl[es]ie dei valde delectabilis...

${ }^{104}$ Se podrá comprobar en las próximas páginas que no siempre coincide la dimensión del volumen descrito en Med. 1673 con la del libro propiedad de Quevedo.

${ }^{105}$ Este libro lo puso a la venta en el año 2008 la librería parisina Jean-Claude Vrain. La referencia y demás datos se toman del catálogo de la librería mencionada [París: Jean-Claude Vrain, 2008?], pág. 27. en él se reproduce la portada de la primera obra en la que se lee la firma de Quevedo, se incluyen dos reproducciones de notas y firmas de Quevedo, en una se lee: «Lat la Cavallere \$/Lat la la ralla \$», y en la otra, realizada en la portada: «d. francisco de Quevedo-Villegas./cauero de la orden de Santiago/vnico Patron despaña/[rúbrica]/ d. francisco-de Queuedo- Villegas [rúbrica]/[rúbrica]». Agradecemos la noticia de este libro a Jonh O'Neil, bibliotecario de la Biblioteca de la Hispanic Society of America.

${ }^{106}$ En esta ocasión la referencia bibliográfica corresponde a la del ejemplar conservado en la Real Biblioteca, descrito en Patrimonio Nacional (España), IBIS [en línea]: Base de datos del patrimonio bibliográfico del Patrimonio Nacional. [Madrid]: Patrimonio Nacional [consulta: 26 de febrero de 2015]. 
Tractatus De magnifice[n]tia glorie Salomonis... Tractatus De duplici causa contritionis... [Fratis Andree de Soncino, ordinis predic.; fratis Jo. Ludo Viualdi de Monte regali]. Venunddantur Lugduni: ad Stephano gueynard prope sanctum Antonium, 1512. Dimensiones: 8 .

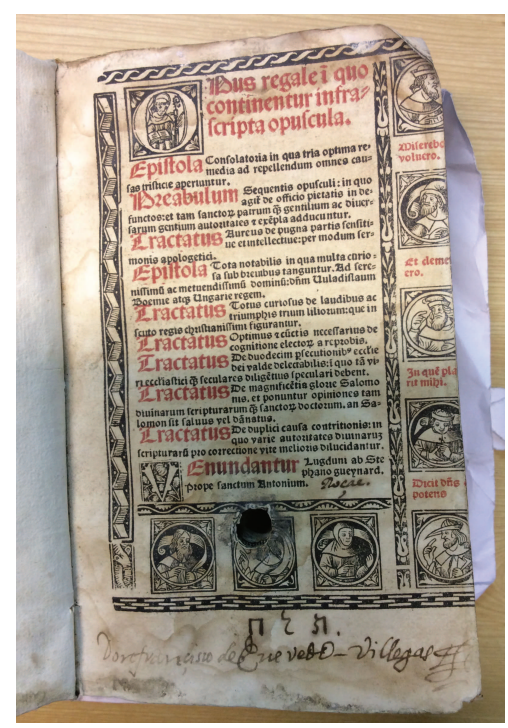

Localización: Parroquia de Santo Domingo de Lucena (Córdoba) ${ }^{107}$.

Firma y rúbrica de Quevedo en portada, sobre ella pueden verse tres caracteres hebreos ${ }^{108}$; también notas autógrafas en varias páginas. El ejemplar ha perdido una encuadernación en plata, sus páginas han sido horadadas para introducir una azucena, atributo de Santo Domingo.

\section{Repertorios:}

- S. Martín 1730, fol. 207v: Vilvaldi (Joannis Ludovici) opus regale theolog. Philosoph. 1288.

- S. Martín 1788, fol. 407v: Vivaldi: Opus Regale. Lugduni.

Esta obra no la hallamos en Med. 1673, sin embargo lo más probable es que este libro pasase de la biblioteca de Quevedo a la del duque y de aquí a Lucena, para convertirse en atributo de Santo Domingo ${ }^{109}$, por tanto, el ejemplar descrito en el

107 Es obligatorio dar encarecidamente las gracias a don Nicolás Jesús Rivero Moreno, párroco de Santo Domingo de Lucena (Córdoba) que no solo nos dio a conocer este libro, sino que además tuvo la amabilidad de trasladarlo hasta el Archivo del Obispado de Córdoba, institución a la que también es nuestro deseo agradecer todas las facilidades dadas para su consulta. Este libro es objeto de un estudio que entregaremos a imprenta próximamente.

108 Ya hemos señalado en este trabajo que estas letras se ven en otros ejemplares.

${ }^{109}$ La ciudad de Lucena fue dominio del señorío de la casa Medinaceli hasta 1770, año en el que pasó a la jurisdicción real. En esta localidad contrajo matrimonio el viII duque de Medinaceli, Juan Francisco de la Cerda Enríquez de Ribera (1637-1691) con la IX duquesa de Segorbe y Cardona, 
índice de San Martín ha de ser otro diferente al firmado y anotado por el escritor madrileño.

\section{BUDE, Guillaume}

Gulielmi Budaei... Altera aeditio Annotationum in Pandectas. Coloniae: opera et impensis Joannis Soteris, Anno 1527. Mense Februario. Dimensiones: 4 .

Localización: BNE, R. 20306.

No conserva signatura topográfica de San Martín, tal vez se haya perdido, pues la $\mathrm{h}$. de guarda no parece de época.

\section{Repertorios:}

- Med. 1673 [475]: Budeo Anotazión sobre las Pandestas, vn tomo en cuarto, en seis reales. ${ }^{110}$

- S. Martín 1730, fol. 37r: Budei (Guilielmi) annotationes in Pandectas.

- S. Martín 1788, fol. 90r: Budei (Guillelmi) Anotationes in Pandectas. Colonia 1527.

No figura esta obra en S. Martín 1699, en el fol. 39v leemos una referencia a otra obra de este autor: «Guillelmo Budes 01 135», y en el fol. 145v se alude al título de la obra: «Cajón 135 Guilielmus Budeus de lingua Graeca 01». En S. Martín 1730, fol. 37r y 1788. fol. 90r se reseña esa obra de S. Martín 1699, indicándose en el último que fue impresa en Basilea, $1580^{111}$.

Como decíamos al comienzo de estas páginas, la labor es lenta y exige grandes dosis de tesón y paciencia, afortunadamente de forma paulatina está aumentando en Ariadna ${ }^{112}$ el número de los impresos anteriores a 1800, lo que nos ha permitido localizar en la BNE un nutrido grupo de ejemplares pertenecientes a la biblioteca particular de Quevedo ${ }^{113}$ :

\section{BARTHOLOMAEUS SIBYLLA}

Speculu[m] peregrinaru[m] quaestionu[m] eruditissimi viri Bartholomei Sibille Monopolinati... Tres decades co[m]plectens in q[ui]bus varie

Catalina Antonia de Aragón Folc de Cardona y Córdoba (1635-1697), quien pudo ser la responsable de la venta de la biblioteca del VII duque a San Martín. Sobre la relación de Lucena con la casa ducal, véanse F. J. López de Cárdenas, Memorias de la ciudad de Lucena y su territorio con varias noticias de erudición pertenecientes a la bética, Imprenta de Benito Daza, Écija, 1777; J. González Moreno, Visión de Lucena a través del archivo de Medinaceli, J. González, Montilla, 1992.

${ }^{110}$ La Biblioteca de la Fundación Bartolomé March posee un ejemplar de esta obra impresa en Basileae: in aedibus Thomae Volffii, 1534 [pie de imprenta tomado de colofón] (signatura B87-A-07) que perteneció a la biblioteca del duque de Medinaceli y Santisteban como atestigua un exlibris, muy posiblemente este libro no fue el que pasó por las manos del VII duque de Medinaceli, sino el firmado por Quevedo descrito aquí.

${ }^{111}$ No hemos localizado ninguna edición de los Commentarii Lingvae Graecae impresos en Basilea, el año de 1580.

112 Biblioteca Nacional (España), Ariadna..., op. cit.

${ }^{113}$ La BNE hace constar en nota los exlibris, sellos, notas manuscritas, etc. que denuncian las procedencias de los ejemplares. 
q[uae] stio[n]es de animalibus rationalibus in co[n]iuncto \& separatis... Impressum Lugduni: in edibus Iacobi Myt, 9 agosto 1521. Dimensiones: 8 .

Localización: R. 21229.

En el recto de la h. de guarda: signatura de San Martín: «C. 286»; en el reverso anotación de Quevedo: «Costó 8 reales»; en portada su firma y rúbrica y tres líneas de su mano ilegibles por haberse escrito sobre ellas. En varios folios del impreso apostillas marginales, subrayados y otras marcas de Quevedo.

\section{Repertorios:}

- Med. 1673 [385]: Bartolomé çiuila Expejo de peregrinas cuestiones, vn tomo en octabo, en ocho reales

- S. Martín 1699, fol. 12v: Bartholome Sibille 01 53; fol. 108v: Cajón 53 Bartolomei Sybili speculum peregrinarum questionum 01

- S. Martín 1730, fol. 188r: Sibilla (Barme) [spe]culum peregrinarum questionum 1330.

- S. Martín 1788, fol. 366v: Sibile (Bartholomei) Speculum peregrinarum Questionum. Lugduni. 1521.

\section{BUXTORF, Johann (1564-1629)}

Joh. Buxtorfi Grammaticae Chaldaicae et Syriacae Libri III: quorum Primus vocum singularum propietatem declarat. Secundus conjuctarum rationem ostendit. Tertius Praxeos Chaldaicae [et] luculenta continet, ex Daniele, Onkelo, Jonathane, ex Targum Hierosolymitano, Talmud Babylonico et Hierosol. ex Zohar, et Versione Novi Testam. Syra... Basileae: Typis Conradi Waldkirchi: impensil Ludouici König, 1615. Dimensiones: 8 .

Localización: BNE, R. 2843.

Firmas y rúbricas de Francisco de Quevedo en portada y última página.

Todos los inventarios e índices registran alguna obra de Johann Buxtorf, pero las descripciones bibliográficas no concuerdan con la del libro que poseyó Quevedo. Med. 1673 tiene dos ítems para obras de este autor [1259 y 1275], que se repiten en los tres índices de S. Martín 1699, 1730 y 1788. El monasterio aumentó considerablemente con el transcurrir de los años el número de obras de Buxtorf, en el primero se describen las mismas dos obras que en Med. 1763, en el segundo más de $10 \mathrm{y}$ en el tercero 17, incluyendo las dos primeras.

\section{CAMERarius, Joachim (1500-1574)}

Commentarius explicationis primi libri Iliados Homeri. Ioachimi Camerarij... Eiusdem libri primi Iliados conuersio in Latinos versus... His Graeca etiam adiecta... Argentoratem: ex oficina Cratonis Muylii, 1538. Dimensiones: 4\%

Localización: BNE, R. 6662.

Texto en latín y griego. En portada: firma y rúbrica de Francisco de Quevedo, le sigue: «Cav. del Ab.-de S. ti»; dos exlibris de la Biblioteca Real; nota manuscrita — no parece de Quevedo—: «Y también hay dentro Galileus Galileij...» 
Encuadernado con las tres obras siguientes:

a) GALILEI, Galileo

D. Galilaei de Galilaeis... De proportionum instrumento a se inuento, quod meritò Compendium dixeris uniuersae geometriae, tractatus rogatu philomathematicorum a Mathia Berneggero ex Italica in Latinam linguam nun primùm translatus... Argentorati: typis Caro li Kiefferi...: apud Ioannem Carolum..., 1612.

En portada sello de la Biblioteca Real. Ejemplar falto de páginas.

b) BobBIO LODOVICO (s. XVI)

Exortatio ad chistianorum principes, de armis adversus orthodoxae fidei hostes, arripiendis autore Bobbio. Perusiae: ex oficina Andreae Brixiani, 1550.

En portada sello de la Biblioteca Real. En el colofón, a mano se corrige el año de impresión: 1555. Anotaciones manuscritas en los márgenes, no parecen de Quevedo.

c) Soто, Domingo de (1495-1560)

Ad máximum atque adeo clarissium Hispaniarum principem. D. Philippum inuictissimi Caesaris Caroli v primogenitum fratris Dominici Soto Segobiensis, theologi ordinis praedicatorum... In causa pauperum deliberatio. Salamanticae: in oficina Ioannis Giuntae, 1545.

Sello de la Biblioteca Real.

No hallamos rastro de este volumen, ni de ninguna de las obras en él encuadernadas, en los repertorios consultados.

\section{CARo, Annibal (1507-1566)}

Apologia de gli Academici di Banchi di Roma, contra M. Lodouico Casteluetro da Modena in forma d'uno Spaccio di Maestro pasquino; con alcune operette, del Pradella, del Buratto, di ser Fedocco. In difesa de la seguente Canzone del Commendatore Annibal Caro. Appertenti tutte à l'vso de la lingua toscana, et al vero modo di poetare. In Parma: in casa di Seth Viotto... del mese di nouembre 1558. Dimensiones: 4 .

\section{Localización: R. 24262.}

En portada: Extensa nota de Quevedo, con rúbrica final (difícil de leer por estar la tinta muy desvaída y escribir hasta el borde de la hoja): «Esta canción no importa nada ni tubo buena actuación quien buscó en ella descuidos porque en la sustancia es diuertida i en la locución mal aliñada dispuesta por el arbitrio de la tinta Castelvetro noto [.......] en ella escritos no son buenos ni [....] dos son [....] mostró este poco seso en las ojeciones i aquel menos este dio en los versos y gastaron mal el papel i el tiempo todos i es contienda de ningún fruto i estudio». Con firma y rúbrica de Quevedo. Signatura del monasterio de San Martín: «C. 142».

\section{Repertorios:}

- Med. 1673 [627]: Apología de las Academias del Maestro Pasquino, vn tomo en quarto, quatro reales. 

Caro 01.

- S. Martín 1699, fol. 7r: Anibal Caro 01 124; fol. 139r: Cajón 124 Anibal

- S. Martín 1730, fol. 47v: [Se inserta con otra mano entre dos entradas:] Caro /Anibal/ Apologia de gli Academia di Banchi de Roma [estante] ${ }^{114} 80$ n. 6.

- S. Martín 1788, fol. 24r: Apologia degli Academici di Banchi, contra M. Ludovico Castelveto [sic]. In Parma, 1573.

A la vista de los resultados obtenidos de la consulta de los repertorios, la lógica conclusión es que el ejemplar ingresó en San Martín, mas tuvieron que desprenderse de ese libro firmado por Quevedo antes de 1788, pues en ese año ya no figuraba en el índice de la biblioteca la edición de 1558, sino una de $1573^{115}$.

\section{Crivellati, Cesare}

Trattato dell'uso et modo di dare il vino nelle malattie acute contra il costume de nostri tempi di Cesare Criuellati... dove si dimostrano le virtu di esso vio, et le cattive qualità dell'Acqua, con il vero modo d'usarla. In Roma: appresso Bartholomeo Bonfadino, per Giouanni Martinelli, 1600 (1599). Dimensiones: 12.

Localización: BNE, R. 21751.

En el recto de la h. de guarda: signatura de San Martín «Caj. 186»; en el reverso anota Quevedo «Costó 8 reales»; en portada firma y rúbrica de Quevedo. El impreso solo tiene una breve apostilla marginal en la p. 12, parece letra de Quevedo.

\section{Repertorios:}

- Med. 1673 [791]: Zésar Cribellati Del vso y modo de dar el vino en las enfermedades, vn tomo en octabo ${ }^{116}$, en quatro reales.

- S. Martín 1699, fol. 18v: César Cribellato 01 194; fol. 170v: Cajón 194 Cessar Cribelatti del vino 01.

- S. Martín 1730, fol. 64v: Crivellati (Cesar) del modo de dar el vino en las enfermedades agudas en toscano 1 [sin número de cajón].

- S. Martín 1788, fol. 145v: Crivellati (Cesar) Del usso de vino, en las Enfermedades agudas. En Italiano. Roma. 1600.

\footnotetext{
114 No tiene la signatura antigua de cajón.

${ }^{115} \mathrm{El}$ Índice alphabético de los libros de poesía castellana, francesa e ytalina de la Bibliotheca del ex.$^{m o}$ s. ${ }^{\text {or }}$ duque de Medina-Celi... año de 1759 (Biblioteca de la Fundación Bartolomé March, signatura B103-V2-1212) registra la misma edición que poseyó Quevedo: «Apología de la academia de Roma contra el M. Ludovico Castelvetro de Módena, algunas operas y tratado del modo de versificar en toscano. Parma 1558», se ha de aceptar en esta ocasión que la obra se vendió al monasterio, pues la signatura antigua — «C. 142»— que conserva el ejemplar así lo prueba.

${ }_{116}$ El inventario de Med. 1673 utiliza para describir el tamaño de los libros los términos: cuarto, folio, marquilla y marca mayor; por tanto, dimensiones empleadas actualmente por las bibliotecas en la descripción de impresos antiguos, como $12^{\circ}$ o $16^{\circ}$, se han de corresponder con alguna de ellas, en este caso la equivalencia hay que establecerla entre $8^{\circ}$ y $12^{\circ}$.
} 


\section{DEMÓSTENES}

Gnomologiai, kai 'omoioseis ek ton tou demosthenous logon te kai epistolon... Gnomologiae id est Sententiae collectaneae et similia ex Demosthenis orationibus et epistolis in certa virtutum ac vitiorum capita collectae authore Ioanne Loino. [Parisiis]: apud Sebastianum Niuellium..., 1551. Dimensiones: $8^{\circ}$.

Localización: R. 20495.

Edición en griego y latín. En portada: firma y rúbrica de Quevedo. Recibe una encuadernación en pergamino moderna, por lo que las primitivas hojas de guarda se han perdido y con ellas las posibles signaturas antiguas de otras bibliotecas, así como otra firma y rúbrica de Quevedo que tuvo en una h. de guarda final, lo que se puede afirmar por haber pasado la tinta de esta a la hoja anterior. Apostillas marginales autógrafas de Quevedo y posiblemente también de su mano los subrayados y marcas que hallamos en varias páginas.

\section{Repertorios:}

-Med. 1673 [1269]: Juan Loyno Sentenzias sobre las orasiones de Demóstenes, vn tomo en quarto ${ }^{117}$, en quatro reales 4.

- S. Martín 1699, fol. 52r: Joan Loyno 01 180; f, 167r: Cajón 180 Joannes Loinus Sententie Demostinis 01.

- S. Martín 1730, fol. 117r: Loini (Joannis) Sententie gre-lat ex Demostinis orationibus 1240.

- S. Martín 1788, fol. 240r: Lorini (Ioannis)... Ejusd Sententiae Collectaneae ex Demostenis orationibus, et Epistolis Collectae. 1551.

Dıon Casius Nicaeus, Aelius Spartianus, Iulius Bapitolinus, Aelius Lampridius, Vulcatius Gallecanus Iohannis Baptistae Egnatij Veneti in eodem annotationes. Parisiis: ex oficina Roberti Stephani..., 1544. Dimensiones: 8 .

Localización: BNE, R. 230.

En portada: firma y dos rúbricas de Francisco de Quevedo; sello de la Biblioteca Real. Impreso con notas autógrafas de Quevedo, hay también otras marcas manuscritas que seguramente han sido realizadas por Quevedo.

No hemos hallado en ninguno de los inventarios e índices obra alguna que corresponda con el libro propiedad de Quevedo.

\section{ESQUILO}

Tragoediae selectae Aeschyli, Sophoclis, Euripidis cum duplici interpretatione Latina, vna ad verbum, altera carmine Ennianae interpretationes locurum

117 Todo parece indicar que el libro que perteneció a Quevedo pasó de su biblioteca a la del duque y de esta a la del monasterio, sin embargo, el tamaño del libro que señala Med. 1673 no coincide con el que perteneció al polígrafo madrileño, o se cometió un error en ese inventario o la procedencia del ejemplar de Quevedo es otra. Lamentablemente el libro en cuestión ha sido encuadernado modernamente, por lo que si en algún momento tuvo signaturas de otras bibliotecas por las que pasó - monasterio de San Martín, por ejemplo- estas se perdieron con las antiguas hojas de guarda. 
aliquot Euripidis. [Ginevra]: excudebat Henr. Stephanus, illustris vir Huldrichi Fuggeri typographus, 1567. Dimensiones: $16^{\circ}$.

Localización: BNE, R. 15678.

En el reverso de la h. de guarda: «14», de mano de Quevedo «costó 15 reales t.»». En portada: firma con dos rúbricas de Quevedo, y exlibris de «D. Joan Martínez Salafranca Presbiteri Turolensis». Tiene algunas anotaciones a mano, no parece letra de Quevedo. En los cortes se lee: «Eurípides».

Como sucede con el libro anterior no hallamos rastro de este en los inventarios e índices consultados. Sin embargo en este, además de la marca de propiedad manuscrita de Quevedo, tenemos la del erudito ilustrado Juan Martínez de Salafranca, capellán de San Isidro, a cuyas manos fue a parar el ejemplar del poeta áureo.

GraPaldi, Francesco Mario (1465?-1515)

Francisci Marij Grapaldi Parmensis, De partibus aedium, Lexicon utilissimum... Basileae: apud Ioan. Vualderum, marzo 1533 (ex oficina Curoniana). Dimensiones: 4 .

Localización: R. 19511.

En h. de portada: Firma y rúbrica de Quevedo; nota de haber sido expurgado: «Corregido conforme al expurg. de 1640 por comissión especial del sr [.....] marzo 24 de 1706». Signatura de San Martín: «C. 136». Dos apostillas marginales, págs. 118 y 144, ambas parecen de Quevedo; en otras págs. subrayados y marcas, probablemente también suyas.

Repertorios: reales.

- Med. 1673 [1104]: Francisco Mario De historia, tomo en quarto, en seis

- S. Martín 1699, fol. 32v: Francisco Mario 01 163; fol. 159r: Cajón 163 Franciscus Marius de partibus aedijs 01.

- S. Martín 1730, fol. 95v: Grapaldi (Francisci Marij) de partibus aedium lexicum 1187.

- S. Martín, 1788, fol. 254r: Marij (Francisci) De partibus Oedium. Basileae. 1533.

La partida de Med. 1673 es probable que no corresponda al libro de Quevedo, a no ser que la materia de la obra de Grapaldi (arquitectura y gramática) haya sido interpretada como historia por el redactor del inventario.

Proclo

Procli insigni philosophi Comendiaria motu disputatio, posteriores quinque Aristotelis de auscultatione naturali libros, mira breuitate complectens. Basileae: per Io. Babelium, et Mich. Ysingrinium, 1531. Dimensiones: 8 .

Localización: R. 24805. 
Texto en griego y prólogo en latín. En el interior de la enc. se anota «3 reales», «12 n. 4». En h. de guarda nota manuscrita de Quevedo. En el reverso de esta, nota firmada por fr. Domingo de Lerín, bibliotecario del monasterio de San Martín ${ }^{118}$. De mano de Quevedo: «Costó 10 reales». En portada: firma y rúbrica de Quevedo. Anotaciones marginales en griego en las pp. 12-26, posiblemente de Quevedo.

Encuadernado con:

\section{a) Dión DE PRUSA}

Dionos Prousaeos sophistou Peri apistias. Dionis Prusaensis sophistae, Non temeré credendum per Ioachimum Cam. latine uersum. Excudebatur Norimbergae: apud Io Petreium, 1531.

Edición en griego y en latín. Quizás de mano de Quevedo, se hacen correcciones a la portada: «Cam. [se inserta: dam natum versum] latine [tachado:] uersum [se añade: auctorem]».

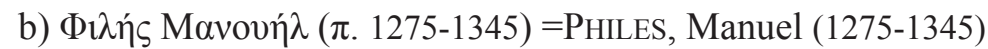

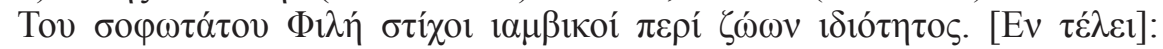

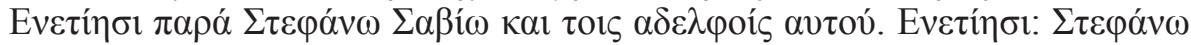
$\Sigma \alpha \beta i ́ \omega,[1533]{ }^{119}$.

Texto en griego.

\section{c) Arístides, Elio}

In libello hoc, insunt. Presbeutikos Aristeidou. Antirrētikos Libaniou. Hoc est. Quid dici amplius ab vlysse legato ad Achillem, \& respo[n]deri ab hoc potuerit vtraque oratio co[n]uersa in latinu[m] a Joach. Camerar. Ejusde[m] \& paraphrasis graeca, Homerici utriusq[ue] loci addita est. Habent studiosi artium egregium exemplum scholasticu[m], cuius, vt opinor, simili non viderunt. Hagan[oae]: [apud Brubachium] ${ }^{120}$, XXXV [i. e. 1533].

Texto en griego y en latín. Parte del título transliterado del griego. Quizás de mano de Quevedo, se hacen correcciones a la portada: «Camerar. [se añade: auctore damnato] Ejusde[m]».

\section{Repertorios $^{121}$ :}

—Med. 1673 [1273]: Proclo sobre Aristóteles, tomo en 4.122 en diez reales.

\footnotetext{
${ }^{118}$ Ha de tratarse del benedictino fray Domingo de Lerín (1748-1809).

119 Versos yámbicos del más sabio Filé en torno a las propiedades de los animales. [Venecia]: Stefano da Sabio y sus hermanos, 1533; el pie de imprenta tomado del colofón. La BNE ha catalogado las dos primeras y última obras que forman parte de este volumen, saltando la impresa en griego. La referencia bibliográfica de esta se copia de la Biblioteca Nacional (Grecia). Catálogo [en línea]. [Atenas]: Biblioteca Nacional. <http://www.nlg.gr/> [consulta: 26 de febrero de 2015].

${ }^{120}$ Impresor tomado del $C C P B E$.

${ }^{121}$ Solo se encuentran referencias a la obra de Proclo en los repertorios consultados.

122 Una vez más encontramos una inconsistencia entre las dimensiones del libro propiedad de Quevedo y el tamaño del descrito en Med. 1673.
} 
- S. Martín 1699, fol. 77v: Proclo 01 194; fol. 170v: Cajón 194 Proclus de moto 01 .

- S. Martín 1730, fol. 165r: Procli motu Dionis de non temere credendo, oratio ad Achilem 1234.

- S. Martín 1788, fol. 324r: Procli Diadochi... Ejusd: Disputatio de motu. Basileae. 1531.

\section{SALVIATI, Leonardo (1540-1589)}

Dello Infarinato accademico della Crusca Rispostata all'apologia di Torquato Tasso intorno all'Orlando furioso, e alla Gierusalèm liberata. In Firenze: per Carlo Meccoli, e Saluestro Magliani, 1585. Dimensiones: 8 .

Localización: BNE, R. 27466.

En h. de guarda, apunta Quevedo: «Costó 5 reales» ${ }^{123}$. En portada: rúbricas de Quevedo a los lados de la marca del impresor, además hay una firma con dos rúbricas suyas. Una nota al margen de la pág. 75 de mano de Quevedo y marcas y subrayados en algunas otras, posiblemente realizas por él.

Repertorios ${ }^{124}$ :

- S. Martín 1788, fol. 335r: Respuesta â la Apologia de Torquato Tasso. en Itno. Florencia. 1585.

\section{SEVERUS ALEXANDRINUS}

D. Seueri Alexandrini quondam Patriarchae De ritibus Baptismi, et sacrae synaxis apud syros chistianos receptis liber. Nun primùm in lucem editus Guidone Frabricio Boderiano excriptore \& interprete. Antuerpiae: ex oficina Christophori Plantini..., 1572. Dimensiones: 4\%.

Localización: R. 26595

Edición en siriaco, latín y hebreo. En h. de guarda: notas manuscritas; signatura de San Martín: «Cajón 7 [corregido por:] 8». En portada firma y rúbrica de Quevedo. En varias páginas marcas o subrayados, posiblemente de Quevedo. Al final, contenido parcial de: Syriacae linguae. Prima elementa. Antuerpiae: ex oficina Crhistophori Plantini..., 1572.

\section{Repertorios:}

—Med. 1673 [877]: Seuero Alejandrino en hebreo, vn tomo en octavo ${ }^{125}$, en ocho reales.

- S. Martín 1699, fol. 83v: Severo Alexandrino 01 01; fol. 92v: Cajón 1 Seuerus Alexandrinus de ritibus Baptismi 01.

${ }^{123}$ No es excepcional que Quevedo anote el coste del libro.

${ }^{124}$ No hemos encontrado ninguna referencia a esta obra ni en Med. 1673 ni en los índices del monasterio S. Martín 1699, 1730 .

${ }^{125}$ No es improbable que esta referencia de Med. 1673 no describa el libro de Quevedo, pues además de la diferencia entre las dimensiones de este y la descrita en el inventario, Med. 1673 no anota que el texto también está en siriaco y en latín, cuando la variedad de lenguas es un aspecto que se reseña en otras partidas. 
- S. Martín 1730, fol. 187v: Severi Patriarche Alexandrie de Ritibus Baptismi, ac sacre sintaxi apud siros xpnos receptis Guidone interp. 18.

- S. Martín 1788, fol. 365v: Severini Alexandrini: De Ritibus Bauptismi, et Sacri Synsis., apud Syros Christianos refectis. Antuerpae. 1572.

A continuación damos noticia de otro grupo menor de libros cuya procedencia es la biblioteca del monasterio benedictino de San Madrid de Madrid, por lo que, aunque no estén firmados por Quevedo, bien pudieron pertenecer a la biblioteca de Antonio Juan Luis de la Cerda y formar parte de esa biblioteca hipotética a la que tuvo acceso el escritor ${ }^{126}$ :

\section{ARISTÓteles}

Aristotelis De poetica liber Daniel Heinsius recensuit, ordini suo restituit, latine vertit, notas addidit; accedit eiusdem De tragica constitutione liber: in quo praeter caetera tota de hac Aristotelis sententia dilucide explicatur. Lugduni Batavorum: apud Ioannem Balduinum, prostat in bibliopolio Ludovici Elzevirij, 1611.

Localización: BNE, 3/47035 127 .

Signaturas manuscritas en el interior de cubierta: «C. 515», corrige: «C. 36»; en h. de guarda: «C. 515».

Repertorios:

- S. Martín 1699, fol. 23r: Daniel Heinsio 01 186; fol. 169r: Cajón 186 Danielis Heinsis Poetica 01.

- S. Martín 1730, fol. 12v: Aristoteles. Eiusdem Poetica cum Heinsio 01204. - S. Martín 1788, fol. 30v: Aristotelis. De Poetica. Lugduni Batavor. 1611.

\section{ARISTóteles}

Historia general de aues y animales de Aristoteles Estagerita; traduzida de latín en romance y añadida de otros muchos autores griegos y latinos... por Diego de Funes y Mendoça... En Valencia: por Pedro Patricio Mey: a costa de Iuan Bautista Marçal, 1621.

Localización: BNE, 2/36958.

Signatura manuscrita en h. de guarda: «C. 181».

\section{Repertorios:}

- S. Martín 1699, fol. 24r: Diego Funes 01 113; fol. 133v: Cajón 113 Diego Funes aves y animales 01 .

${ }^{126}$ En páginas anteriores se ha hecho referencia algún otro ejemplar de San Martín hasta ahora desconocido, que no se incluye en esta parte para no repetir: obras de Botero y Frachetta (BNE, 3/29030), Fioravanti (BNE, 3/76931) y Aristóteles (BNE, 2/36115).

127 De este ejemplar dio noticia I. Pérez Cuenca, «Entre Quevedo y Medinaceli». En Med. 1673 no encontramos referencia a esta obra. Moya del Baño, op. cit., pág. 415, lo incluye en sus listados con la indicación «este lo tuvo Quevedo». No hay en el impreso ninguna nota o marca que confirme que este libro pasó por sus manos. 
- S. Martín 1730, fol. 12v: Aristóteles. Eiusdem hist. general de las Aves y animales traducida en castellano 1.

- S. Martín 1788, fol. 182v: Funes (Dn Diego). Historia Genl Aues y Animales. Valencia. 1621.

\section{DU BELLAY, Martin}

Mart. Bellaii Langaei... Commentariorum de rebus Gallicis, libri decem ex Gallico Latini facti ab Hugone Suraeo... Francofurti: apud Andream Wechelum, 1575.

En el colofón: Francofurti ad moenum, exudeban Andreas Wechelus, anno salutis, 1574.

Localización: BNE, 2/70430.

Signatura manuscrita en h. de guarda: «C. 157», tachado: «Caj ${ }^{\mathrm{n}} 115 »$.

Repertorios:

- S. Martín 1730, fol. 22r: Bellai (Martini) de rebus Gallicis $1157^{128}$.

- S. Martín 1788, fol. 55v: Bellay (Mart) De Rebus Galicis. Francofurti. 1574 et 1575 .

\section{HOMERO}

Homeri quae exstant omnia Ilias, Odyssea, Batrachomyomachia, Hymni, Poématia aliquot cum latina versione... perpetuis item iustisque in Iliada simul et Odysseam Io. Spondani... commentariis; Pindari quin etiam thebani Epitome Iliados...; Daretis Phrygii De bello troiano libri; à Corn. Nepote eleganter latino versi carmine... Basileae: per Sebastianum Henricpetri, 1606. Dimensiones: folio.

Localización: BNE, 7/11800 129 .

En h. de guarda: «C. 208» [?] [corregido: 7]. En el verso de port: «expurgué este libro del señor don Fran ${ }^{\text {co }}$ de Calatayud ${ }^{130}$ conforme al nuevo cathálogo por comisión que para ello tengo de la general inqusición, en Sevilla en 13 de mayo de 1616 años. Pedro de Lazcano [rúbrica]». En portada, nota manuscrita: «1397 [rúbrica]; expurgado conforme al expurgo de 1707, fr. Plácido Morales [rúbrica]».

\section{Repertorios:}

- S. Martín 1699, 54r: Joan Spondano 01 177; fol. 166r: Cajón 177 Joannes Spondanus in Homerum 01.

${ }^{128}$ Nótese la coincidencia entre el número de cajón asignado a esta obra en el inventario de S. Martín 1730 y la signatura topográfica que figura en la hoja de guarda del ejemplar de la BNE.

${ }^{129}$ Moya del Baño, op. cit., pág. 431, nota 89, identifica la edición de esta obra de Homero, señala que se encuentra en S. Martín 1788 y localiza un ejemplar de ella en la BNE (R. 407) que, según anota lleva una marca de pertenencia: «B. Aldrete». Pero no es ese el ejemplar de San Martín, sino el que registramos aquí. Ninguno de los dos tiene marcas o apostillas que induzcan a pensar que fueron empleados por Quevedo.

${ }^{130}$ En el año 1616 el libro es propiedad de Francisco de Calatayud y Sandoval, escritor cercano a Olivares. Véase J. Montero Delgado, «Olivares y los ingenios andaluces. Sobre el mecenazgo literario del conde duque», Andalucía en la Historia, abril de 2012, 16-19, pág. 18. 
- S. Martín 1730, fol. 102v: Homero Poemata grec-lat notis variorum 1207. - S. Martín 1788, fol. 210r: Homero. Opera. Basileae. 1606.

En Quev. 1646 [180/152] leemos: «Homere, Ombras suas [sic], fo, en veinte y quatro reales», Maldonado ${ }^{131}$, siguiendo a S. Martín 1788, identifica el ítem del inventario de Quevedo con esta edición de 1606132. En Med. 1673 hay dos partidas para obras de Homero, una — [806] — está totalmente descartada por tratarse de una edición en francés, y la otra - [799]— por establecer el tamaño del libro en octavo.

\section{PÉREZ DE MOYA, Juan (Ca. 1513-1596)}

Tratado de Mathemáticas en que se contienen cosas de Arithmética, Geometría, Cosmographía y Philisophía natural... ordenado por... Iuan Pérez de Moya... En Alcalá de Henares: por Iuan Gracián, 1573.

Localización: BNE, R/22928

En una h. de guarda y en la portada figura la signatura manuscrita: «C. 670».

\section{Repertorios:}

- S. Martín 1730, fol. 156r: Pérez (Juan Moya). Aritmética iten Gramática [sin número de cajón. Sobre la línea se escribe:] duplicado.

- S. Martín 1788, fol. 310r: Pérez de Moya (Juan). Tratado de Mathem ${ }^{\text {ca }}$. Alcalá de Henares, 1573.

Dudamos de que este ejemplar pertenezca al monasterio de San Martín porque, en primer lugar, la mano que asigna la signatura topográfica es muy diferente a la de las signaturas de otros libros vistos del monasterio y, en segundo, en S. Martín 1699 y 1730 el número de cajones es muy inferior al de $670^{133}$. Este libro debió pertenecer a una biblioteca con un gran número de libros con igual o similar sistema de organización que el de los benedictinos.

\section{Clavius, Christoph (1537-1612)}

Gnomonices libri octo In quibus non solum horologium solarium sed aliarum quoque rerum, quae ex gnominis umbra cognosci possunt, descriptions geometrice demonstrantur auctore Christophoro Clauio... Societatis Iesu... Romae: apud Frnciscum Zanettum, 1581. Dimensiones: folio.

Localización: BNE, R. 20128.

Marcas de procedencia: «fr. Martín Sarmiento - Benedictino»; «este libro es de Pedro García Noriega Vicario App co s por su S pa s Ill pma s»; también

${ }^{131}$ F. R. C. Maldonado, op. cit., pág. 427.

${ }^{132}$ C. Fernández y S. Simões, op. cit., pág. 41, no tienen propuesta nueva y repiten la de Maldonado.

${ }^{133}$ Sabemos que en 1730 la biblioteca del monasterio aún empleaba el sistema de cajón, pues así lo refleja el índice fechado en ese año, pero hemos de tener en cuenta que, primero, en ese mismo índice se anotan las signaturas nuevas que las sustituyen de estante y número $\mathrm{y}$, segundo, un conjunto amplio de ítems se insertan con letra diferente a la empleada en la redacción de 1730 y estos solo señalan la nueva signatura. 
una nota manuscrita da indicaciones para que el libro sea entregado al Padre Predicador Balboa, en el real monasterio de San Martín de Madrid.

- S. Martín 1699, fol. 19r: Christobal Clavio 01 58; fol. 110r: Cajón 58 Christophorus Clavius in Euclidem 02.

- S. Martín 1730, fol. 58r: Clavij (Christophori)... [se inserta, con otra mano:] ítem Gnomonice [sobre la línea, estante] 45, n. 4.

- S. Martín 1788, fol. 132r: Clavij (Christophori)... Eujsd: Gnomonices. Romae. 1581.

En S. Martín 1699 no se corresponde el número de tomos que se indican en el ítem del autor (fol. 19r) con los registrados en el cajón (fol. 110r), posiblemente no se trate de la misma obra. Las anotaciones de procedencia parecen indicar que esta obra perteneció a la colección particular de Martín Sarmiento, benedictino de San Martín, de ser así, hay que descartarla del catálogo de la biblioteca hipotética de Quevedo.

Son muchos los problemas que surgen en el proceso de identificación de las ediciones y localización de los ejemplares que pudieron pasar por las manos de Francisco de Quevedo. Los trabajos que sobre la biblioteca de Quevedo se han sucedido en los últimos 20 han aportado un número considerable de libros que añadir a la colección particular del escritor y un mayor conocimiento sobre sus lecturas, aprovechamiento de ellas y proceso creativo. Aún así, los resultados son parciales y las conclusiones provisionales. Una vez que tengamos identificadas la mayoría de ediciones registradas en estos repertorios, muy especialmente Quev. 1646, Med. 1673 y S. Martín 1788 estaremos más cerca de su biblioteca hipotética, sin olvidar que queda una parte de su colección de la que desconocemos las manos que la poseyó tras su muerte. Tampoco se ha de olvidar la necesidad de registrar la información sobre las lecturas realizadas por Quevedo que sus escritos nos proporcionan, como han hecho para los padres de la iglesia Sagrario López Poza y para los clásicos grecolatinos Francisca Moya del Baño en los trabajos ya citados; solo sumando ambos procesos veremos el rompecabezas de su biblioteca hipotética cerca de estar completo. 
